THE BACE1 PRODUCT SAPP $\beta$ INDUCES ER STRESS AND INFLAMMATION AND IMPAIRS

\title{
INSULIN SIGNALING
}

Gaia Botteri ${ }^{1,2,3,4}$, Laia Salvadó ${ }^{1,2,3,4}$, Anna Gumà ${ }^{2,3,5}$, D. Lee Hamilton ${ }^{6}$, Paul J. Meakin ${ }^{6}$, Gemma Montagut $^{6}$, Michael L.J. Ashford ${ }^{6}$, Victoria Ceperuelo-Mallafré ${ }^{3,7}$, Sonia Fernández-Veledo ${ }^{3,7}$, Joan Vendrell $^{3,7}$, María Calderón-Dominguez ${ }^{2,8,9}$, Dolors Serra ${ }^{2,8,9}$, Laura Herrero ${ }^{2,8,9}$, Javier Pizarro ${ }^{1,2,3,4}$, Emma Barroso ${ }^{1,2,3,4}$, Xavier Palomer ${ }^{1,2,3,4}$, and Manuel Vázquez-Carrera ${ }^{1,2,3,4}$

${ }^{1}$ Pharmacology Unit, Department of Pharmacology, Toxicology and Therapeutic Chemistry, Faculty of Pharmacy and Food Sciences, University of Barcelona. ${ }^{2}$ Institut de Biomedicina de la Universitat de Barcelona (IBUB). ${ }^{3}$ Centro de Investigación Biomédica en Red de Diabetes y Enfermedades Metabólicas Asociadas (CIBERDEM), Instituto de Salud Carlos III, Barcelona, Spain. ${ }^{4}$ Institut de Recerca Sant Joan de Déu (IR-SJD), Esplugues de Llobregat, Barcelona. ${ }^{5}$ Department of Biochemistry and Molecular Biology, Faculty of Biology, University of Barcelona, Barcelona, Spain. ${ }^{6}$ Division of Molecular and Clinical Medicine, School of Medicine, Ninewells Hospital \& Medical School, University of Dundee, Dundee, UK. ${ }^{7}$ Hospital Universitari de Tarragona Joan XXIII, Institut d'Investigació Sanitària Pere Virgili, Universitat Rovira i Virgili, Tarragona, Spain. ${ }^{8}$ Department of Biochemistry and Physiology, Faculty of Pharmacy and Food Sciences, University of Barcelona. ${ }^{9}$ Centro de Investigación Biomédica en Red de Fisiopatología de la Obesidad y la Nutrición (CIBEROBN), Instituto de Salud Carlos III, Barcelona, Spain

Keywords: BACE1, CREB, insulin resistance, NF-кB, palmitate, PGC-1 $\alpha$, sAPP $\beta$.

Corresponding author: Manuel Vázquez-Carrera. Unitat de Farmacologia. Facultat de Farmàcia. Avinguda Joan XXIII 27-31. E-08028 Barcelona. Spain. Phone 93 4024531. Fax 934035982

E-mail: mvazquezcarrera@ub.edu 


\begin{abstract}
Objective

$\beta$-secretase/ $\beta$-site amyloid precursor protein (APP)-cleaving enzyme 1 (BACE1) is a key enzyme involved in Alzheimer's disease that has recently been implicated in insulin-independent glucose uptake in myotubes. However, it is presently unknown whether BACE1 and the product of its activity, soluble APP $\beta$ (SAPP $\beta$ ), contribute to lipid-induced inflammation and insulin resistance in skeletal muscle cells.
\end{abstract}

\title{
Materials/Methods
}

Studies were conducted in mouse $\mathrm{C} 2 \mathrm{C} 12$ myotubes, skeletal muscle from Bace ${ }^{-/}$mice and mice treated with SAPP $\beta$ and adipose tissue and plasma from obese and type 2 diabetic patients.

\section{Results}

We show that BACE1 inhibition or knockdown attenuates palmitate-induced endoplasmic reticulum (ER) stress, inflammation, and insulin resistance and prevents the reduction in Peroxisome ProliferatorActivated Receptor $\gamma$ Co-activator $1 \alpha($ PGC-1 $\alpha)$ and fatty acid oxidation caused by palmitate in myotubes. The effects of palmitate on ER stress, inflammation, insulin resistance, PGC-1 $\alpha$ down-regulation, and fatty acid oxidation were mimicked by soluble APP $\beta$ in vitro. BACE1 expression was increased in subcutaneous adipose tissue of obese and type 2 diabetic patients and this was accompanied by a decrease in PGC- $1 \alpha$ mRNA levels and by an increase in SAPP $\beta$ plasma levels of obese type 2 diabetic patients compared to obese non-diabetic subjects. Acute SAPP $\beta$ administration to mice reduced PGC-1 $\alpha$ levels and increased inflammation in skeletal muscle and decreased insulin sensitivity.

\section{Conclusions}

Collectively, these findings indicate that the BACE1 product sAPP $\beta$ is a key determinant in ER stress, inflammation and insulin resistance in skeletal muscle and gluconeogenesis in liver. 


\section{Introduction}

The primary site of insulin stimulated glucose disposal is skeletal muscle, which can account for up to $90 \%$ of glucose clearance [1]. As a result, loss of skeletal muscle insulin sensitivity is believed to be critical in the pathogenesis of type 2 diabetes mellitus (T2DM) [2,3]. In fact, one of the earliest detectable defects in individuals at risk of T2DM is impaired skeletal muscle insulin sensitivity [4,5]. A range of evidence suggests that insulin resistance in skeletal muscle is induced by increased levels of plasma non-esterified free fatty acids (NEFAs) [6,7] and/or changes in adipokine levels caused by obesity [8]. It has long been recognized that elevated plasma NEFA levels cause insulin resistance in humans [9]. The mechanisms underlying the association between elevated NEFA and insulin resistance are currently unclear, but accumulating evidence points to a link between enhanced NEFA levels and activation of a chronic lowlevel inflammatory process $[8,10]$. Elevated saturated NEFA can induce inflammation, and thus insulin resistance, through several mechanisms, including accumulation of fatty acid (FA) derivatives (such as ceramide and diacylglycerol) due to an increased FA flux in skeletal muscle cells that exceeds their $\beta$ oxidation capacity [11,12], activation of toll-like receptors [13], and endoplasmic reticulum (ER) stress $[14,15]$. Of note, all these mechanisms converge in the activation of pro-inflammatory signaling pathways, including I $\kappa \mathrm{B}$ kinase $\beta$ (IKK- $\beta$ )-nuclear factor $(\mathrm{NF})-\kappa \mathrm{B}$, which has been linked to FA-induced impairment of insulin action in skeletal muscle [16,17]. Thus, IKK- $\beta$ phosphorylates IRS-1 on serine residues, attenuating the insulin signaling pathway, whereas once activated, NF- $\kappa \mathrm{B}$ regulates the expression of multiple inflammatory mediators, including interleukin 6 (IL-6), monocyte chemoattractant protein 1 (MCP-1), and tumor necrosis factor $\alpha$ (TNF- $\alpha$ ), which also contribute to insulin resistance [10]. Recent evidence also points to a possible defect in mitochondrial function induced by FA overload. For instance, short-term exposure to high circulating FA impairs the mitochondrial membrane potential [6] and tissue culture studies demonstrate that palmitate overload induces mitochondrial dysfunction associated with reduced oxidative capacity [17]. Mitochondrial function is transcriptionally controlled by peroxisome proliferator-activated receptor $\gamma$ co-activator $1 \alpha(\mathrm{PGC}-1 \alpha)[18]$ and plays a critical role in skeletal muscle metabolic function. Some $[19,20]$ but not all [21] studies indicate a reduction in PGC-1 $\alpha$ expression and or 
function in the skeletal muscle of prediabetic and diabetic subjects. Collectively, these data indicate a possible molecular link between elevated circulating FA and the impaired mitochondrial function sometimes noted in the skeletal muscle of those at risk of T2DM.

Interestingly, some Alzheimer's disease (AD) patients exhibit impaired glucose metabolism, hyperinsulinemia, and insulin resistance [22,23], suggesting that some common pathways may be involved in the development of both diseases. $\beta$-secretase/ $\beta$-site amyloid precursor protein (APP)-cleaving enzyme 1 (BACE1) is a key enzyme involved in AD that has recently been implicated in insulin-independent glucose metabolism [24]. APP is first cleaved by either BACE1 or $\alpha$-secretase enzyme, generating extracellular soluble APP $\beta$ ( $\mathrm{sAPP} \beta$ ) or sAPP $\alpha$, respectively. Following BACE1 cleavage, the APP C-terminal fragment C99 can be cleaved by $\gamma$-secretase, raising the levels of amyloid- $\beta$ (A $\beta$ ) peptides and leading to amyloid aggregation and plaque formation [25]. It has been reported that BACE1-deficient mice are protected against high-fat diet (HFD)-induced glucose intolerance [26], although the mechanisms involved remain unclear. More recently, it has been shown that inhibition of muscle BACE1 activity increases insulinindependent glucose uptake and GLUT4 translocation [24]. Of note, the saturated FA palmitate and ceramide increase $\mathrm{BACE} 1$ protein levels in $\mathrm{C} 2 \mathrm{C} 12$ myotubes [24], probably by post-translational stabilization of the protein [27], suggesting that $\beta$-secretase might contribute to the effects of saturated NEFA on inflammation and insulin resistance in skeletal muscle cells. In the present study, we examined whether BACE1 activity and its product sAPP $\beta$ contribute to insulin resistance in skeletal muscle. 


\section{Materials and Methods}

\subsection{Cell culture}

Mouse C2C12 myoblasts (ATCC) were maintained in Dulbecco's modified Eagle's medium (DMEM) supplemented with $10 \%$ fetal bovine serum (FBS), 50 units/ml penicillin and $50 \mathrm{mg} / \mathrm{ml}$ streptomycin. When cells reached confluence, the medium was switched to the differentiation medium containing DMEM and $2 \%$ horse serum, which was changed every other day. After 4 additional days, the differentiated $\mathrm{C} 2 \mathrm{C} 12$ cells had fused into myotubes. Lipid-containing media were prepared by conjugation of non-esterified fatty acids (NEFA) with NEFA-free bovine serum albumin. Briefly, palmitic acid was dissolved in ethanol and diluted 1:100 in DMEM containing 2\% (w/v) NEFA-free bovine serum albumin. Myotubes were incubated in serum-free DMEM containing $2 \%$ bovine serum albumin in either the presence (palmitate-treated cells) or absence (control cells) of NEFA. Cell viability was assessed using the LDH Cytotoxicity Assay Kit from Thermo Scientific (Waltham, MA, USA).

Human LHCN-M2 myoblasts were maintained, grown and differentiated to myotubes as previously described [28].

\subsection{Mice}

Male Bace ${ }^{-1}$ mice and wild-type (WT) littermate controls on the C57B16/J background were sacrificed under isoflurane anesthesia. WT and Bace ${ }^{-1-}$ mice were fed a standard diet or a high-fat diet (HFD) containing, by energy, $45 \%$ fat, $20 \%$ protein and $35 \%$ carbohydrate (catalogue number $58 \mathrm{~V} 8$, TestDiet $\circledast$, Purina Mills) for 20 weeks. Skeletal muscle (gastrocnemius) and epididymal adipose tissue samples were frozen in liquid nitrogen and then stored at $-80^{\circ} \mathrm{C}$. For quantification of sAPP $\beta$, plasma and skeletal muscle were obtained from mice fed a standard diet or a HFD (Research Diets D08061110) for 3 months. For quantification of sAPP $\beta$ and A $\beta 42$, plasma of these mice was concentrated (30 kDa Amicon Ultra $15 \mathrm{ml}$ filter) by centrifugation and subjected to SDS-PAGE.

In a second study male C57BL/6 mice were randomly distributed into two groups ( $\mathrm{n}=6$ each) and intramuscular (gastrocnemius) injection of vehicle (PBS plus $4 \%$ urea) or $5 \mu \mathrm{g}$ of sAPP $\beta$ was performed. Twelve hours later animals were sacrificed and the skeletal muscle gastrocnemius was excised. 
In a third study male C57BL/6 mice were randomly distributed into two groups ( $\mathrm{n}=6$ each) and vehicle or

$10 \mu \mathrm{g}$ of sAPP $\beta$ was administered (i.p.) twice $(20.00 \mathrm{~h}$ and $8.00 \mathrm{~h})$ before starting either a glucose tolerance test (GTT) or an insulin tolerance test (ITT). In the GTT animals received $2 \mathrm{~g} / \mathrm{Kg}$ body weight of glucose by ip injection, and blood was collected from the tail vein after 0, 15, 30, 60 and $120 \mathrm{~min}$. In the ITT each animal received $0.5 \mathrm{IU} / \mathrm{Kg}$ of body weight of insulin.

All animal care, experimental protocols and procedures were performed in accordance to the Animal Scientific Procedures Act (1986), with approval of the University of Barcelona and Dundee ethics committees.

\subsection{Subjects}

Subjects were recruited by the Endocrinology Department at the University Hospital Joan XXIII (Tarragona, Spain) in accordance with the Helsinki Declaration (2008). All participants gave their informed consent and the study was approved by the respective local Ethic Committee review board of the participating Hospital. Donors were classified as lean or obese based on body mass index (BMI) following World Health Organization criteria (WHO). T2D subjects were diagnosed according WHO criteria. All patients had fasted overnight before collection of blood samples. Anthropometric and biochemical variables from the two cohorts used are presented in Supplementary Tables S1 and S2. All subjects were of white origin and reported that their body weight had been stable for at least 3 months prior to the study. They had no systemic disease other than obesity, and all had been free of infection in the previous month before the study. Primary liver disease, cardiovascular disease, arthritis, acute inflammatory disease, infectious disease, neoplastic and renal diseases were specifically excluded by biochemical evaluation. Serum was immediately separated by centrifugation and stored at $-80^{\circ} \mathrm{C}$ until analysis. Subjects were stratified according to age, gender and BMI. The hospital ethics committee approved the study and informed consent for biobanking surgically removed tissue was obtained from all participants in accordance with the Declaration of Helsinki. All patients had fasted overnight before collection of adipose tissue and blood. Visceral (VAT) and subcutaneous (SAT) adipose tissue was obtained during scheduled non-acute surgical procedures including laparoscopic surgery for hiatus hernia repair or cholecystectomies. 
Serum fasting glucose, insulin, triglycerides, total cholesterol and high-density lipoprotein were determined

by standard enzymatic methods. Insulin resistance was estimated using homeostasis model assessment index-insulin resistance (HOMA-IR). For clinical and anthropometrical variables, normal distributed data were expressed as mean value $\pm \mathrm{SD}$, and variables with no Gaussian distribution values were expressed as median (25th-75th quartiles). For analysis of expression variables that do not follow a Gaussian distribution, values were analyzed by non-parametrical tests (Kruskal-Wallis). When data were normally distributed, differences in clinical variables, laboratory parameters or expression variables between groups were compared by ANOVA with post hoc Scheffe correction.

Total RNA was extracted from adipose tissue using the RNeasy Lipid Tissue Midi Kit (Qiagen Science, Hilden, Germany). Total RNA quantity was measured at $260 \mathrm{~nm}$ and purity was assessed by the OD260/OD280 ratio. One microgram of RNA was reverse transcribed with random primers using the Reverse Transcription System (Applied Byosistems, Foster City, CA). Quantitative gene expression was evaluated by Real-time PCR (qPCR) on a 7900HT Fast Real-Time PCR System using TaqMan Low Density Arrays (Applied Biosystems, micro fluidic cards) (BACE1 Hs01121195_m1 and PPARGC1A Hs01016719_m1). Results were calculated using the comparative Ct method (2- DD Ct), and expressed relative to the expression of the housekeeping genes cyclophilin 1A (PPIA) (Hs 04194521_s1) and 18S (Hs 03928985_g1).

For western blot analysis of sAPP $\beta$ in human serum samples, serum albumin and the major subclasses of gamma globulin (IgG) were removed using Amicon Ultra-0.5 centrifugal Filter devices (Millipore) following Pierce Albumin/IgG Removal Kit (Pierce Biotechnology, Boston, MA).

\subsection{RNA preparation and quantitative Real-Time RT-PCR}

The relative levels of specific mRNAs were assessed by Real Time RT-PCR, as previously described [28]. Primer sequences used are displayed in supplemental Table S3. 


\subsection{Immunoblotting}

Isolation of total and nuclear extracts was performed as described elsewhere [28]. Western blot analysis was performed using antibodies against total and phospho-Akt $\left(\mathrm{Ser}^{473}\right)$, adenylate cyclase, BACE1, CHOP, total and phospho-CREB $\left(\operatorname{Ser}^{133}\right)$, total and phospho-eIF2 $\alpha$, GRP78/BiP, insulin receptor $\beta$-subunit (IRß), NRF1, total and phospho-PKA $\left(\mathrm{Thr}^{197}\right)$, total and p-STAT3 $\left(\mathrm{Tyr}^{705}\right)($ Cell Signaling Technology Inc., Danvers, MA), OXPHOS (Mito Sciences, Eugene, OR), A $\beta 42$ (Biolegend), sAPP $\beta$ (Covance, Alnwick, UK), PGC-1 $\alpha$ (Abcam, Cambridge, United Kingdom), GAPDH, IкB $\alpha$, lamin B, Oct-1, p65, PPAR $\alpha, \operatorname{PPAR} \beta / \delta$, prohibitin (Santa Cruz), total and phospho-IRS-1 $\left(\mathrm{Ser}^{307}\right)$ (Millipore, Billerica, MA) and $\beta$-actin (Sigma, St. Louis, MO). Detection was achieved using the Western Lightning® Plus-ECL chemiluminescence kit (PerkinElmer, Waltham, MA). The equal loading of proteins was assessed by Ponceau S staining. The size of detected proteins was estimated using protein molecular-mass standards (Bio-Rad, Hercules, CA). For validation, we used a protein marker (Precision Plus Protein Dual Color Standards 1610374; Bio-Rad, Hercules, CA, USA), on the same blots. All of these commercially available antibodies showed a single distinct band at the molecular weight indicated in the datasheets.

\subsection{Electrophoretic mobility shift assay (EMSA)}

The electrophoretic mobility shift assay (EMSA) was performed as previously described [28].

\subsection{Fatty acid oxidation (FAO) assay}

Total FAO was measured as previously described [29].

\subsection{Protein kinase A (PKA) activity and cAMP levels}

Commercial kits were used to assess PKA activity (Enzo Life Sciences, Farmingdale, NY) and cAMP levels (Biovision, Milpitas, CA).

\subsection{Deoxy-D-glucose, $2-\left[1,2-{ }^{3} \mathrm{H}(\mathrm{N})\right]$ uptake experiments}


Cells were starved for $24 \mathrm{~h}$ and washed twice with HEPES buffer (20 mmol/l HEPES [pH 7.4], $140 \mathrm{mmol} / \mathrm{l}$ $\mathrm{NaCl}, 2.5 \mathrm{mmol} / \mathrm{l} \mathrm{MgSO} 4,5 \mathrm{mmol} / \mathrm{l} \mathrm{KCl}, 1 \mathrm{mmol} / \mathrm{l} \mathrm{CaCl} 2)$. Cells were preincubated with HEPES buffer for $1 \mathrm{~h}$ and incubated for $30 \mathrm{~min}$ in the presence or absence of $100 \mathrm{nmol} / \mathrm{l}$ insulin, followed by treatment with deoxy-D-glucose,2-[1,2- $\left.{ }^{3} \mathrm{H}(\mathrm{N})\right]$ (37,000 Bq/ml; Amersham Biosciences) for $20 \mathrm{~min}$. The uptake was stopped by adding $10 \mu \mathrm{mol} / 1$ cytochalasin $\mathrm{B}$. After washing with ice-cold $0.9 \% \mathrm{NaCl}$ three times, cells were lysed with $0.1 \mathrm{~mol} / \mathrm{l} \mathrm{NaOH}$. Non-specific uptake was measured in the presence of $10 \mu \mathrm{mol} / 1$ cytochalasin B and was subtracted from all the values.

\subsection{Pyruvate tolerance test (PTT)}

For PTT analysis, mice were fasted for $15 \mathrm{~h}$ and intraperitoneally injected with pyruvate $(2 \mathrm{~g} / \mathrm{Kg})$. Blood was taken from tail vein at $0,15,30,45,60,75,90,105$, and 120 min after pyruvate injection and blood glucose was measured with a glucometer.

\subsection{Statistical Analyses}

Results were normalised to levels in control groups and are expressed as means \pm S.D. Significant differences were established by either the Student's t test or one-way and two-way ANOVA, according to the number of groups compared, using GraphPad Prism software (GraphPad Software Inc. V4.03, San Diego, CA). When significant variations were found by two-way ANOVA, the Tukey-Kramer multiple comparison post-test was performed. Differences were considered significant at $\mathrm{P}<0.05$. 


\section{Results}

\subsection{Palmitate increases Bace1 expression through an NF- $\mathrm{kB}$-dependent mechanism}

It has been previously reported that palmitate treatment increases BACE1 protein levels in $\mathrm{C} 2 \mathrm{C} 12$ myotubes through post-translational stabilization of BACE1 protein caused by palmitate and ceramide [24,27]. However, it was unknown whether transcriptional mechanisms were involved. Interestingly, palmitate increased Bace1 mRNA levels in $\mathrm{C} 2 \mathrm{C} 12$ myotubes (Figure 1A). Since palmitate increases NF-kB activity in myotubes [12] and Bace1 is under the transcriptional control of NF- $\mathrm{KB}$ [30], we evaluated whether palmitate-induced NF-kB activation was responsible for the increase in Bace1 expression by using the NF-kB inhibitor parthenolide [31]. Parthenolide prevented the palmitate-induced increase in Bace1 mRNA levels (Figure 1B), suggesting that palmitate increases its expression by activating NF-kB. Therefore, the observed increase in BACE1 protein levels following palmitate exposure (Figure 1C) might be the result of the reported post-translational stabilization of BACE1 protein [24,27], but also of Bace1 increased expression. When mice were fed a HFD we also observed an increase in the mRNA and protein levels of BACE1 in the skeletal muscle and white adipose tissue of these mice compared to those fed a standard diet (Figure 1D-G), suggesting that the transcriptional mechanism may also operate in vivo.

\subsection{BACE1 inhibition prevents palmitate-induced ER stress, inflammation, and insulin resistance}

Next, we hypothesized that BACE1 might contribute to some of the deleterious effects of palmitate, including ER stress, inflammation, and insulin resistance. To elucidate this, we used the BACE1 inhibitor Merck-3 (M3), reported to inhibit BACE1 activity in C2C12 cells [24,27]. M3 treatment significantly attenuated the palmitate-mediated increase in the expression of ER stress markers (sXbp1, Atf3, Chop, and Bip) (Figures 2A and B). Given the association of ER stress with inflammation and insulin resistance [15], we also evaluated the effect of M3 on palmitate-induced Tnf- $\alpha$ and II-6 expression. The increase in IL-6 and Tnf- $\alpha$ expression caused by palmitate was significantly blunted in the presence of M3 (Figure 2B). As expected, palmitate exposure reduced protein levels of the NF- $\mathrm{BB}$ inhibitor I $\mathrm{KB} \alpha$, whereas in the presence of palmitate plus M3, this reduction was blunted (Figure 2C). Consistent with this, the nuclear protein 
levels of the NF- $\kappa B$ subunit p65 were raised by palmitate, but this increase was abolished when cells were co-incubated with the FA and M3 (Figure 2C). Likewise, NF-kB DNA-binding activity increased (complex I) in nuclear extracts from palmitate-exposed cells, whereas the binding activity in cells co-incubated with palmitate and M3 was similar to that observed in control cells (Figure 2D).

When we evaluated the insulin signaling pathway, we observed that, in agreement with a previous study reporting that ER stress reduced insulin receptor (IR) levels in adipocytes [32], protein levels of IR $\beta$ were reduced in palmitate-exposed cells, which was prevented by M3 (Figure 2E). In line with activation of the NF- $\kappa \mathrm{B}$ pathway, IRS1 phosphorylation at $\mathrm{Ser}^{307}$ was increased in palmitate-exposed cells and this was blocked by M3 (Figure 2E). Finally, palmitate reduced insulin-stimulated Akt phosphorylation, whereas this reduction was reversed in cells co-incubated with palmitate and M3 (Figure 2F).

\subsection{BACE1 inhibition prevents the reduction in Pgc-1 $\alpha$ expression caused by palmitate}

PGC-1 $\alpha$ regulates the activity of several transcription factors that control the expression/function of genes involved in FAO, including PPAR $\alpha$ and PPAR $\beta / \delta$ [33]. Since palmitate increases BACE1 protein levels and we reported that this FA reduces the expression of Pgc-1 $\alpha$ [12], we next evaluated whether BACE1 inhibition prevented the reduction in Pgc- $1 \alpha$ levels. Palmitate caused a reduction in Pgc- $1 \alpha$ mRNA levels that was prevented by M3 (Figure 2G). Similarly, PGC-1 $\alpha$ protein levels showed a significant reduction in palmitate-exposed cells, but this reduction was not observed when cells where co-incubated with palmitate plus M3 (Figure 2H). In agreement with these changes, palmitate induced a reduction in the mRNA and protein levels of PPAR $\alpha$ and PPAR $\beta / \delta$, which in turn regulate Pgc- $1 \alpha$ expression [34], but their levels were restored in cells co-incubated with palmitate plus M3 (Figure 2G and H). The expression of PPARtarget genes such as Acox, Cpt- $1 \alpha$ and Mcad, as well as $\mathrm{I} k \mathrm{~B} \alpha$, which is also under the transcriptional control of PPAR $\alpha$ [35], were reduced by palmitate (with the exception of Cpt-1 $\alpha$ ) and restored when cells were incubated with the FA plus M3 (Figure 2I). Given that PGC-1 $\alpha$ regulates PPAR $\alpha$ transcriptional activity [36], we assessed the DNA-binding activity of this transcription factor by performing EMSA. PPAR $\alpha$ DNA-binding activity (complex I) was reduced by palmitate, in agreement with the reduction in 
PGC-1 $\alpha$ protein levels, whereas this reduction was partially prevented in cells co-incubated with palmitate and M3 (Figure 2J). It is worth pointing out that incubation of the cells only with the M3 compound significantly increased mRNA levels of $\operatorname{Ppar} \alpha, \operatorname{Ppar} \beta / \delta, \operatorname{Pgc}-1 \alpha$, and the PPAR-target gene Cpt- $1 \alpha$ (Supplementary Figure 1A), suggesting that basal expression of these genes may be repressed by BACE1 activity.

\subsection{Bace1 knockdown increases PGC-1 $\alpha$ in myotubes and skeletal muscle}

To clearly demonstrate that BACE1 modulates PGC-1 $\alpha$, we used genetic approaches. Knockdown of Bace1 by siRNA transfection in C2C12 cells (Supplementary Figure 1B and C) led to a significant increase in the expression and the protein levels of PGC- $1 \alpha$, PPAR $\alpha$, and PPAR $\beta / \delta$ (Figure $3 \mathrm{~A}$ and B). In addition, expression of the PPAR-target genes Cpt-1 $\alpha$, Acox and Mcad was significantly increased by Bace1 knockdown, whereas expression of Chop, Tnf- $\alpha$, and Mcp-1 were reduced (Figure 3C). Moreover, IкB $\alpha$ and IR $\beta$ protein levels were also increased, whereas phospho-IRS1 $\left(\mathrm{Ser}^{307}\right)$ levels were decreased (Figure 3D). In agreement with this, a significant increase in PGC-1 $\alpha$ expression and protein levels in skeletal muscle from Bace1-deficient mice was observed (Figures 3E and F). Moreover, PPAR $\alpha$ and PPAR $\beta / \delta$ expression and protein levels were also enhanced. Likewise, the expression of $\mathrm{I} k \mathrm{~b} \alpha, \mathrm{Cpt}-1 \alpha$, Acox, and Mcad was increased in Bace1-deficient mice, whereas Mcp-1, Tnf- $\alpha$, and Chop expression was decreased compared with wild-type littermates (Figure 3G). Similarly, the protein levels of IKB $\alpha$ and IR $\beta$ were increased in the skeletal muscle of Bace1-deficient mice compared with wild-type littermates, whereas phospho-eIF2 $\alpha$, which induces Chop levels, and phospho-IRS1 $\left(\mathrm{Ser}^{307}\right)$ were decreased (Figure 3H).

\subsection{Bace1 knockdown prevents the reduction in PGC1 $\alpha$ expression and the inflammatory process caused by a HFD in skeletal muscle}

When we evaluated the effects of a HFD in the skeletal muscle of wild-type and BACE1-deficient mice, a reduction in Pgc-1 $\alpha$ expression was observed in wild-type mice fed a HFD, but the increase in the expression of this co-activator displayed in $\mathrm{BACE}^{-/-}$mice prevented the reduction in Pgc- $1 \alpha$ mRNA levels 
when these mice were fed a HFD (Figure 3I). Consistent with the reduction in Pgc-1 $\alpha$ expression, Ppar $\alpha$ mRNA levels were also down-regulated in the skeletal muscle of wild-type mice fed a HFD, whereas this reduction was prevented in $\mathrm{BACE} 1^{-/}$mice fed the HFD. Likewise, the HFD reduced I $\kappa \mathrm{b} \alpha$ expression, whereas that of Tnf- $\alpha$ and Il-6 was increased in wild-type mice and these changes were prevented in BACE1-deficient mice fed a HFD (Figure 3I).

\subsection{SAPP $\beta$ mimics the effects of palmitate}

BACE1 cleaves APP releasing sAPP $\beta$, which we hypothesized might be responsible for the effects caused by BACE1 in palmitate-exposed cells. SAPP $\beta$ concentration was selected after performing curveconcentration studies (Supplementary Figures 1D-G). sAPP $\beta$ caused a reduction similar to that caused by palmitate in Pgc-1 $\alpha$ mRNA (Figure 4A) and protein levels (Figure 4B). In agreement with this, the mRNA levels of Ppar $\alpha$ and $\operatorname{Ppar} \beta / \delta$ and several of their target genes involved in FAO, including Cpt- $1 \alpha$, Acox and Mcad were decreased by sAPP $\beta$ (Figure 4A). The effect of sAPP $\beta$ on the expression of these genes differed from that of palmitate only in the case of Cpt-1 $\alpha$ expression. No changes were observed in the expression levels of $\mathrm{Cpt}-1 \alpha$, Acox, Mcad and $\operatorname{Ppar} \beta / \delta$ when myotubes were exposed to sAPP $\alpha$, whereas, in contrast to sAPP $\beta, \operatorname{Pgc}-1 \alpha$ and Ppar $\alpha$ expression was increased (Supplementary Figure 2A). Consistent with the reported regulation of mitochondrial oxidative phosphorylation (OXPHOS) genes by PGC$1 \alpha$ [37], palmitate and sAPP $\beta$ reduced the protein levels of complexes I, II, III, IV and V (Figure 4C). In addition, sAPP $\beta$ elicited a significant increase in the expression of Atf3, Chop, Tnf- $\alpha$, and IL-6, whereas I $\mathrm{B} \alpha \alpha$ expression was reduced (Figure 4D). Likewise, sAPP $\beta$ caused an increase in nuclear p65 protein levels, a reduction in IR $\beta$, an increase in phospho-IRS1 $\left(\mathrm{Ser}^{307}\right)$ and a consequent reduction in insulinstimulated Akt phosphorylation, identical to that observed for palmitate (Figures 4E-H). No changes were observed in the expression or protein levels of ER stress and inflammation markers following sAPP $\alpha$ treatment (Supplementary Figures 2B and C). Consistent with the reduction in the attenuation of the insulin signaling pathway, sAPP $\beta$ also reduced insulin-stimulated glucose uptake, whereas sAPP $\alpha$ did not (Figure 4I). Since our findings indicate that BACE1 activity and sAPP $\beta$ regulate the expression of genes involved 
in FAO, we next determined whether the changes in the expression of these genes affected FAO in

myotubes exposed to palmitate in the presence or absence of M3 and to sAPP $\beta$. Palmitate significantly reduced FAO and this effect was blunted by co-incubation with M3, while sAPP $\beta$ caused a reduction in FAO similar to that observed for palmitate (Figure 4J).

\subsection{BACE1 expression and plasma SAPP $\beta$ levels are increased in type 2 diabetic patients}

Next, we explored whether the relationship between BACE1 and PGC-1 $\alpha$ was also observed in humans. In subcutaneous white adipose tissue (WAT) BACE1 expression was increased in obese and especially in type 2 diabetic patients compared with lean subjects (Figure 5A). Interestingly, this increase was accompanied by a reduction in PGC- $1 \alpha$ mRNA levels. These changes were not observed in visceral WAT, where the expression of BACE1 was higher than in subcutaneous WAT (Supplementary Figures 2D). Interestingly, mice fed a HFD exhibited higher plasma sAPP $\beta$ levels compared to mice fed a standard diet, whereas no changes were observed in A $\beta 42$ (Figure 5B). In humans, although no changes were observed between obese and lean subjects (Figure 5C), a significant increase was observed in plasma sAPP $\beta$ levels from type 2 diabetic patients compared with obese non-diabetic subjects (Figure 5D). Interestingly, a unique intramuscular injection of sAPP $\beta$ in gastrocnemius muscle resulted in an increase in the expression of Chop and Atf3, whereas BiP levels were not affected (Figure 5E). sAPP $\beta$ also upregulated Tnf $\alpha$ and Il-6 expression (Figure 5F), whereas a reduction in Pgc-1 $\alpha$ and Ppar $\alpha$ mRNA levels was observed (Figure 5G). Likewise, PGC-1 $\alpha$ and I $\mathrm{I} B \alpha$ protein levels were decreased in skeletal muscle following in situ administration of sAPP $\beta$, while phospho-eIF2 $\alpha$ and BiP protein levels were enhanced (Figure 5H).

\section{8. sAPP $\beta$ administration to mice induces ER stress, inflammation and reduces PGC-1 $\alpha$}

Surprisingly, intraperitoneal acute administration of sAPP $\beta(10 \mu \mathrm{g} /$ mouse $)$ before $(20.00 \mathrm{~h})$ and after $(8.00$ h) an overnight fasting to conduct a GTT resulted in a reduction in blood glucose levels (Figure 6A) and decreased the AUC of plasma glucose levels in the GTT (Figure 6B). In contrast, the AUC of plasma glucose levels was increased by sAPP $\beta$ in the ITT, indicating a reduction in insulin sensitivity (Figure 6B). 
sAPP $\beta$ administration caused an increase in the plasma levels of this peptide (Supplementary Figure 2E)

similar to that caused by HFD and this led to upregulation of Atf3, Tnf $\alpha$ and IL- 6 expression in skeletal muscle, whereas no significant changes were observed in $\mathrm{BiP}$ and Chop (Figure 6C). Consistent with the increased expression of inflammatory markers, the protein levels of $\operatorname{I\kappa B} \alpha$ were decreased by sAPP $\beta$ administration, whereas BiP protein abundance was increased (Figure 6D). sAPP $\beta$ administration also reduced Pgc- $1 \alpha$ expression and protein levels and the mRNA abundance of Ppar $\alpha$ in skeletal muscle (Figures 6E-F). Consistent with the reduction in insulin sensitivity suggested by the ITT, IR $\beta$ protein abundance was reduced and the levels of phospho-IRS1 $\left(\mathrm{Ser}^{307}\right)$ were enhanced by sAPP $\beta$ in skeletal muscle (Figure 6G). In epididymal white adipose tissue we observed similar changes to those reported in skeletal muscle following sAPP $\beta$ treatment (Supplementary Figure 2H). Given the discrepancy between the GTT and the ITT, we examined sAPP $\beta$ effects in liver. Hepatic Pgc- $1 \alpha$, Ppar $\alpha$ and I $k$ b $\alpha$ expression, protein levels of PGC-1 $\alpha$ and of its downstream transcription factor, nuclear respiratory factor 1 (NRF-1), and proteins of the insulin signaling pathway, were reduced by sAPP $\beta$ (Figure 6H-J). In contrast, Bip, Chop and $\operatorname{Tnf} \alpha$ expression was upregulated (Figure 6H). PGC-1 $\alpha$ promotes hepatic gluconeogenesis by regulating the expression of rate-limiting gluconeogenic genes such as PEPCK and G6Pase [38] and in agreement with the reduction in plasma glucose levels and in hepatic Pgc- $1 \alpha$ expression in mice treated with sAPP $\beta$, these mice also exhibit a reduction in hepatic Pepck and G6Pase expression (Figure 6H). To clearly demonstrate that sAPP $\beta$ affects gluconeogenesis in liver we performed a PTT. As shown in Figure $6 \mathrm{~K}$, sAPP $\beta$ repressed glucose synthesis from pyruvate.

\subsection{BACE1 regulates CREB phosphorylation}

Next, we focused on the potential mechanisms by which BACE1 and sAPP $\beta$ regulate the expression of Pgc-1 $\alpha$, since its reduction seems to be the main step driving the changes caused by palmitate-induced upregulation of $\beta$-secretase. Pgc-1 $\alpha$ expression is regulated by the transcription factor CREB [39,40]. CREB is activated following phosphorylation at $\operatorname{Ser}^{133}$ by PKA, which is allosterically activated by cAMP [41]. Phosphorylated CREB then interacts with the transcription co-activator CREB-binding protein to initiate 
the transcription and translation of CREB-target genes, such as Pgc-1 $\alpha$ [33]. Of note, it has previously been reported that elevated BACE1 protein levels reduce CREB phosphorylation, PKA activity, and cAMP levels in neuroblastoma cells and rat primary cortical neurons, contributing to memory and cognitive deficits typical of AD [42]. We hypothesized that palmitate-induced BACE1 protein levels might affect CREB phosphorylation, leading to decreased Pgc- $1 \alpha$ expression, which contributes to reduce FAO, thereby exacerbating inflammation and insulin resistance. First, we examined whether BACE1 inhibition and sAPP $\beta$ affected the PKA/CREB pathway. Exposure to palmitate and SAPP $\beta$ reduced phospho-CREB $\left(\operatorname{Ser}^{133}\right)$ levels, whereas the reduction caused by palmitate was prevented by pre-treatment with M3 (Figures 7A and B). Consistent with this, increased levels of phospho-CREB were observed following Bace1 knockdown in myotubes and in skeletal muscle of $\mathrm{BACE}^{-1-}$ mice (Figures $7 \mathrm{C}$ and D). Exposure to palmitate reduced phospho-protein levels $\left(\mathrm{Thr}^{197}\right.$ ) of the catalytic subunit of PKA (Figure 7E), which is required for full catalytic activity of this kinase [43], and this reduction was blunted by M3. sAPP $\beta$ caused a stronger reduction in phospho-PKA protein levels than that observed for palmitate (Figure 7F). Likewise, Bace1 knockdown in myotubes and BACE1-deficiency in skeletal muscle resulted in increased levels of phospho-PKA (Figure 7G and H). In addition, PKA activity was reduced following exposure to sAPP $\beta$ and palmitate, the latter being reversed by pre-treatment with M3 (Figure 7I). Finally, cells exposed to palmitate and sAPP $\beta$ also showed a reduction in cAMP levels, whereas M3 pre-treatment prevented the reduction caused by the FA (Figure 7J). Moreover, Chen et al. [42] demonstrated that BACE1 may also reduce the cAMP/PKA/CREB pathway by interacting with adenylate cyclase. To examine whether palmitate affects the interaction between BACE1 and adenylate cyclase, we performed protein coimmunoprecipitation. In agreement with the increase in protein levels caused by palmitate, this FA raised the interaction between adenylate cyclase and BACE1, whereas this increase was prevented in cells exposed to palmitate plus M3 (Figure 7K).

We then examined whether sAPP $\beta$ also affected the interaction between BACE1 and AC. Interestingly, mice treated with SAPP $\beta$ showed an increase in the protein levels of BACE1 in skeletal muscle (Figure $8 \mathrm{~A})$, suggesting that it has a similar effect to that shown for palmitate. In addition, $\operatorname{sAPP} \beta$ enhanced the 
expression of Bace1 and reduced the mRNA levels of Pgc- $1 \alpha$ in $\mathrm{C} 2 \mathrm{C} 12$ myotubes and these changes were prevented by the NF- $\mathrm{kB}$ inhibitor parthenolide, suggesting that they were dependent on the activation of this transcription factor (Figure 8B). Likewise, the protein levels of both BACE1 and PGC-1 $\alpha$ showed the same behavior (Figure 8C). Finally, co-immunoprecipitation studies demonstrated that $\mathrm{C} 2 \mathrm{C} 12$ myotubes exposed to sAPP $\beta$ showed enhanced interaction between BACE1 and AC and that this interaction was prevented by parthenolide (Figure 8D). Moreover, this interaction was also increased in the skeletal muscle of mice treated with sAPP $\beta$ (Figure 8E).

\section{Discussion}

The findings of the present study indicate that the increase in BACE1 levels caused by palmitate can contribute to lipid-induced ER stress, inflammation, and insulin resistance in skeletal muscle cells and these effects can be attenuated by BACE1 inhibition. Our findings demonstrate that the BACE1 product sAPP $\beta$ mimicked most of the effects of palmitate. This is the first time these network interactions have been demonstrated and add an important dimension to the mechanisms driving insulin resistance.

The changes caused by palmitate and sAPP $\beta$ might be the result of the reduction in PGC- $1 \alpha$. Furthermore, the effects observed in skeletal muscle from Bace1-deficient mice confirmed that BACE1 contributes to reduce PGC-1 $\alpha$ levels. This transcriptional co-activator preserves OXPHOS genes [37] and co-activates and increases the expression of transcription factors involved in FAO, such as PPAR $\alpha$ and PPAR $\beta / \delta$ $[33,34]$. Therefore, the reduction in PGC- $1 \alpha$ levels caused by palmitate and sAPP $\beta$ may reduce FAO, increasing the amount of palmitate available and ultimately exacerbating ER stress, inflammation, and insulin resistance. In addition, PGC-1 $\alpha$ has a role in inflammation in skeletal muscle. For instance, PGC$1 \alpha$ knockout mice show higher basal mRNA expression of Tnf- $\alpha$ and Il-6 in skeletal muscle compared with wild-type mice [44-46]. 
Although it has been reported that $\mathrm{A} \beta 42$ induces hepatic insulin resistance by activating the JAK2/STAT3/SOCS1 pathway [47], we did not observe changes in these pathway in C2C12 myotubes exposed to sAPP $\beta$ or in mice treated with this peptide (Supplementary Figure 3).

On the other hand, despite it has been previously reported that PGC-1 $\alpha$ regulates Bace1 promoter in neurons [48], in myotubes this mechanism does not seem operate, since when Pgc-1 $\alpha$ was overexpressed in human LHCN-M2 cells, no changes were observed in the expression of Bace1 (Supplementary Figure 4). On the other hand, CREB binding to the PGC- $1 \alpha$ promoter plays a key role in activating PGC- $1 \alpha$ expression in skeletal muscle [33], and a previous study reported that BACE1 reduces CREB phosphorylation in neurons [42]. In addition, CREB is phosphorylated by PKA following activation by cAMP. Our findings suggest that BACE1 activity down-regulates PGC-1 $\alpha$ levels by attenuating the cAMPPKA-CREB pathway. In neurons, there are conflicting results about whether the effects of BACE1 on the cAMP/PKA/CREB pathway are dependent on its enzymatic activity and A $\beta$ levels [42,49]. Tong et al. [49] reported that A $\beta-(1-42)$ suppressed CREB phosphorylation in cortical neurons. In contrast, Chen et al. [42] demonstrated that enhanced BACE1 levels reduced CREB phosphorylation, PKA activity, and cAMP content in neurons and mouse brains, and that these effects were independent of BACE1 activity and A $\beta$ levels. These latter authors reported that BACE1 interacts via its transmembrane domain with adenylate cyclase to inactivate the cAMP/PKA/CREB pathway. Our findings also show that palmitate exposure, likely as the result of the increase in BACE1 protein levels, enhances its interaction with adenylate cyclase, a mechanism that may also contribute to reduce cAMP levels, as previously reported [42]. Although it has been reported that endogenous carnitine stores in L6 myotubes are low [50] and this may lead to cytotoxic responses of the myocytes when incubated for 24 with palmitate alone, we did not observe differences in cell viability or in some of the parameters analyzed in the absence or in the presence of carnitine for $16 \mathrm{~h}$ (Supplementary Figure 5). 
The levels of sAPP $\beta$ were increased in plasma of mice fed a HFD, which is consistent with the reported increase in myotubes incubated with the FA-derivative ceramide [24], whereas the levels of $A \beta-42$ were not altered. In humans we found that BACE1 expression was increased in the subcutaneous WAT of obese and, especially in type 2 diabetic patients compared with lean subjects and this increase was accompanied by a reduction in PGC- $1 \alpha$ mRNA levels. In agreement with the increase in BACE1 expression in subcutaneous WAT, sAPP $\beta$ plasma levels were also enhanced in obese type 2 diabetic patients compared with obese non-diabetic subjects. The lack of increase in obese subjects compared with lean subjects suggests that the increase in the levels of plasma sAPP $\beta$ might be associated with the transition from obesity to T2DM. Acute administration of sAPP $\beta$ to mice elicited similar effects to those observed in vitro, causing an upregulation of the markers of ER stress, inflammation and insulin resistance in skeletal muscle. Interestingly, our findings show that sAPP $\beta$ mimics the effects of palmitate and both increase the levels of BACE1 through an NF- $\kappa B$-dependent mechanism. In fact, it has been reported that NF- $\mathrm{B}$ increases BACE1 expression by promoter transactivation [30]. Moreover, inhibition of NF- $\mathrm{KB}$ prevented the interaction between BACE1 and AC. Therefore, these data suggest that palmitate and sAPP $\beta$ increase the protein levels of BACE1 and as a result of this increase BACE1 binds and inhibits the activity of AC, ultimately leading to the reduction of the cAMP-PKA-CREB pathway and the reduction in Pgc- $1 \alpha$ expression (Figure 8E).

Mice treated with sAPP $\beta$ showed a reduction in insulin sensitivity in the ITT, but surprisingly, plasma glucose levels were reduced by sAPP $\beta$ administration. No significant changes were observed in insulin levels during the GTT (Supplementary Figure 6). In liver, PGC-1 $\alpha$ promotes hepatic gluconeogenesis [43], and sAPP $\beta$ reduced hepatic PGC-1 $\alpha$ levels and the expression of genes regulated by this transcriptional coactivator involved in gluconeogenesis. Since PGC-1 $\alpha$ has opposite effects on hepatic and muscle insulin sensitivity [51], and gluconeogenesis strongly contributes to sustain plasma glucose levels under fasting conditions, for instance when glycogen stores are low after an overnight fast, the net result of a decrease in PGC- $1 \alpha$ levels following sAPP $\beta$ treatment is a reduction in plasma glucose levels. 
On the basis of our findings, we propose that BACE1 and its product sAPP $\beta$ contribute to lipid-induced ER stress, inflammation, and insulin resistance in skeletal muscle, and that targeting BACE1 may provide a new therapeutic option for the prevention and treatment of insulin resistance and T2DM.

\section{Funding}

This study was partly supported by funds from the Spanish Ministerio de Economía y Competitividad (SAF2012-30708 and SAF2015-64146-R to MVC, SAF2013-45887-R to LH, SAF2014-52223-C2-1-R to DS, SAF2015-65019-R to SFV and PI14/00228 to JV), the Generalitat de Catalunya (2014SGR-13 to MVC and 2014SGR465 to DS), Diabetes UK Grants (Grant nos. 08/0003681 and 12/0004458 to MLJA), European Union ERDF funds, and the European Foundation for the Study of Diabetes (EFSD)/JanssenRising Star and L'Oréal-UNESCO "For Women in Science" research fellowships to LH. CIBER de Diabetes y Enfermedades Metabólicas Asociadas (CIBERDEM) is an Instituto de Salud Carlos III project (Grant CB07/08/0003 to MVC and CB07/08/0012 to JV). CIBER Fisiopatología de la Obesidad y la Nutrición (CIBEROBN) (Grant CB06/03/0001 granted to DS). GB was supported by a FPI grant from the Spanish Ministerio de Economía y Competitividad. SFV acknowledges support from the Miguel Servet tenure-track program (CP10/00438 and CPII16/00008) from the Fondo de Investigación Sanitaria (FIS) cofinanced by the ERDF. We would like to thank the University of Barcelona's Language Advisory Service for revising the manuscript.

\section{Conflicts of Interest}

The authors have no conflicts of interest associated with this manuscript. 


\section{Author's contribution}

GB, LS, AG, AMGF, DLH, SFV, PJM, GM, MLJA, MCD, DS, LH, EB, XP and MVC processed the samples, analyzed and prepared the data, and were involved in drafting the article. GB, AG, GM, MLJA, SFV, JV, DS, LH, and XP contributed to data interpretation and revised the article. MVC designed the experiments, interpreted the data, and was primarily responsible for writing the manuscript. All authors approved the final version of the manuscript.

\section{References}

1. DeFronzo RA, Gunnarsson R, Björkman O, Olsson M, Wahren J. Effects of insulin on peripheral and splanchnic glucose metabolism in noninsulin-dependent (type II) diabetes mellitus. J Clin Invest 1985;76:149-155.

2. Kelley DE, Goodpaster BH, Storlien L. Muscle triglyceride and insulin resistance. Annu Rev Nutr 2002;22:325-346.

3. Abdul-Ghani MA, DeFronzo RA. Pathogenesis of insulin resistance in skeletal muscle. J Biomed Biotechnol 2010:476279.

4. Savage DB, Petersen KF, Shulman GI. Disordered lipid metabolism and the pathogenesis of insulin resistance. Physiol Rev 2007;87:507-520.

5. Rothman DL, Magnusson I, Cline G, Gerard D, Kahn CR, Shulman RG, Shulman GI. Decreased muscle glucose transport/phosphorylation is an early defect in the pathogenesis of non-insulindependent diabetes mellitus. Proc Natl Acad Sci U S A 1995;92:983-987.

6. Daniele G, Eldor R, Merovci A, Clarke GD, Xiong J, Tripathy D, Taranova A, Abdul-Ghani M, DeFronzo RA. Chronic reduction of plasma free fatty acid improves mitochondrial function and whole-body insulin sensitivity in obese and type 2 diabetic individuals. Diabetes 2014;63:28122820.

7. Chavez AO, Kamath S, Jani R, Sharma LK, Monroy A, Abdul-Ghani MA, Centonze VE, Sathyanarayana P, Coletta DK, Jenkinson CP, Bai Y, Folli F, Defronzo RA, Tripathy D. Effect of short-term free Fatty acids elevation on mitochondrial function in skeletal muscle of healthy individuals. J Clin Endocrinol Metab 2010;95:422-429.

8. Schenk S, Saberi M, Olefsky JM. Insulin sensitivity: modulation by nutrients and inflammation. J Clin Invest 2008;118:2992-3002.

9. Boden G. Role of fatty acids in the pathogenesis of insulin resistance and NIDDM. Diabetes 1997;46:3-10.

10. Wellen KE, Hotamisligil GS. Inflammation, stress, and diabetes. J Clin Invest 2005;115:11111119.

11. Coll T, Eyre E, Rodríguez-Calvo R, Palomer X, Sánchez RM, Merlos M, Laguna JC, VázquezCarrera M. Oleate reverses palmitate-induced insulin resistance and inflammation in skeletal muscle cells. J Biol Chem 2008;283:11107-1116.

12. Chaurasia B, Summers SA. Ceramides - Lipotoxic Inducers of Metabolic Disorders. Trends Endocrinol Metab 2015;26:538-550.

13. Senn JJ. Toll-like receptor-2 is essential for the development of palmitate-induced insulin resistance in myotubes. J Biol Chem 2006;281:26865-26875. 
14. Salvadó L, Coll T, Gómez-Foix AM, Salmerón E, Barroso E, Palomer X, Vázquez-Carrera M. Oleate prevents saturated-fatty-acid-induced ER stress, inflammation and insulin resistance in skeletal muscle cells through an AMPK-dependent mechanism. Diabetologia 2013;56:1372-1382.

15. Salvadó L, Palomer X, Barroso E, Vázquez-Carrera M. Targeting endoplasmic reticulum stress in insulin resistance. Trends Endocrinol Metab 2015;26:438-448.

16. Kim JK, Kim YJ, Fillmore JJ, Chen Y, Moore I, Lee J, Yuan M, Li ZW, Karin M, Perret P, Shoelson SE, Shulman GI. Prevention of fat-induced insulin resistance by salicylate. J Clin Invest 2001;108:437-446.

17. Lipina C, Macrae K, Suhm T, Weigert C, Blachnio-Zabielska A, Baranowski M, Gorski J, Burgess $\mathrm{K}$, Hundal HS. Mitochondrial substrate availability and its role in lipid-induced insulin resistance and proinflammatory signaling in skeletal muscle. Diabetes 2013;62:3426-3436.

18. Handschin C, Spiegelman BM. Peroxisome proliferator-activated receptor gamma coactivator 1 coactivators, energy homeostasis, and metabolism. Endocr Rev 2006;27:728-735.

19. Patti ME, Butte AJ, Crunkhorn S, Cusi K, Berria R, Kashyap S, Miyazaki Y, Kohane I, Costello M, Saccone R, Landaker EJ, Goldfine AB, Mun E, DeFronzo R, Finlayson J, Kahn CR, Mandarino LJ. Coordinated reduction of genes of oxidative metabolism in humans with insulin resistance and diabetes: Potential role of PGC1 and NRF1. Proc Natl Acad Sci U S A 2003;100:8466-8471.

20. Mootha VK, Lindgren CM, Eriksson KF, Subramanian A, Sihag S, Lehar J, Puigserver P, Carlsson E, Ridderstråle M, Laurila E, Houstis N, Daly MJ, Patterson N, Mesirov JP, Golub TR, Tamayo P, Spiegelman B, Lander ES, Hirschhorn JN, Altshuler D, Groop LC. PGC-1alpha-responsive genes involved in oxidative phosphorylation are coordinately downregulated in human diabetes. Nat Genet 2003;34:267-273.

21. Gallagher IJ, Scheele C, Keller P, Nielsen AR, Remenyi J, Fischer CP, Roder K, Babraj J, Wahlestedt C, Hutvagner G, Pedersen BK, Timmons JA. Integration of microRNA changes in vivo identifies novel molecular features of muscle insulin resistance in type 2 diabetes. Genome Med 2010;1;2:9.

22. Janson J, Laedtke T, Parisi JE, O'Brien P, Petersen RC, Butler PC.Increased risk of type 2 diabetes in Alzheimer disease. Diabetes 2004;53:474-481.

23. Strachan MW, Reynolds RM, Marioni RE, Price JF. Cognitive function, dementia and type 2 diabetes mellitus in the elderly. Nat Rev Endocrinol 2001;7:108-114.

24. Hamilton DL, Findlay JA, Montagut G, Meakin PJ, Bestow D, Jalicy SM, Ashford ML. Altered amyloid precursor protein processing regulates glucose uptake and oxidation in cultured rodent myotubes. Diabetologia 2014;57:1684-1692.

25. LaFerla FM, Green KN, Oddo S. Intracellular amyloid-beta in Alzheimer's disease. Nat Rev Neurosci 2007;8:499-509

26. Meakin PJ, Harper AJ, Hamilton DL, Gallagher J, McNeilly AD, Burgess LA, Vaanholt LM, Bannon KA, Latcham J, Hussain I, Speakman JR, Howlett DR, Ashford ML. Reduction in BACE1 decreases body weight, protects against diet-induced obesity and enhances insulin sensitivity in mice. Biochem J 2012;441:285-296.

27. Puglielli L, Ellis BC, Saunders AJ, Kovacs DM. Ceramide stabilizes beta-site amyloid precursor protein-cleaving enzyme 1 and promotes amyloid beta-peptide biogenesis. J Biol Chem 2003;278:19777-19783.

28. Salvadó L, Barroso E, Gómez-Foix AM, Palomer X, Michalik L, Wahli W, Vázquez-Carrera M. $\mathrm{PPAR} \beta / \delta$ prevents endoplasmic reticulum stress-associated inflammation and insulin resistance in skeletal muscle cells through an AMPK-dependent mechanism. Diabetologia 2014;57:2126-2135.

29. Herrero L, Rubí B, Sebastián D, Serra D, Asins G, Maechler P, Prentki M, Hegardt FG. Alteration of the malonyl-CoA/carnitine palmitoyltransferase I interaction in the cell impairs glucose-induced insulin secretion. Diabetes 2005;54:462-471.

30. Buggia-Prevot V, Sevalle J, Rossner S, Checler F. NFkappaB-dependent control of BACE1 promoter transactivation by Abeta42. J Biol Chem 2008;283:10037-10047.

31. Hehner SP, Heinrich M, Bork PM, Vogt M, Ratter F, Lehmann V, Schulze-Osthoff K, Dröge W, Schmitz ML. Sesquiterpene lactones specifically inhibit activation of NF-kappa B by preventing the degradation of I kappa B-alpha and I kappa B-beta. J Biol Chem 1998;273:1288-1297. 
32. Zhou L, Zhang J, Fang Q, Liu M, Liu X, Jia W, Dong LQ, Liu F. Autophagy-mediated insulin receptor down-regulation contributes to endoplasmic reticulum stress-induced insulin resistance. Mol Pharmacol 2009;76:596-603.

33. Kang C, Li Ji L. Role of PGC-1 $\alpha$ signaling in skeletal muscle health and disease. Ann N Y Acad Sci 2012;1271:110-117.

34. Hondares E, Pineda-Torra I, Iglesias R, Staels B, Villarroya F, Giralt M. PPARdelta, but not PPARalpha, activates PGC-1alpha gene transcription in muscle. Biochem Biophys Res Commun 2007;354:1021-1027.

35. Buroker NE, Barboza J, Huang JY. The IkappaBalpha gene is a peroxisome proliferator-activated receptor cardiac target gene. FEBS J 2009;276:3247-3255.

36. Vega RB, Huss JM, Kelly DP. The coactivator PGC-1 cooperates with peroxisome proliferatoractivated receptor alpha in transcriptional control of nuclear genes encoding mitochondrial fatty acid oxidation enzymes. Mol Cell Biol 2000;20:1868-1876.

37. Wenz T, Rossi SG, Rotundo RL, Spiegelman BM, Moraes CT. Increased muscle PGC-1alpha expression protects from sarcopenia and metabolic disease during aging. Proc Natl Acad Sci U S A 2009; 106:20405-20410.

38. Yoon, J.C., P. Puigserver, G. Chen, J. Donovan, Z. Wu, J. Rhee, G. Adelmant, J. Stafford, C.R. Kahn, D.K. Granner, et al. 2001. Control of hepatic gluconeogenesis through the transcriptional coactivator PGC-1. Nature 413:131-138.

39. Wu Z, Huang X, Feng Y, Handschin C, Feng Y, Gullicksen PS, Bare O, Labow M, Spiegelman B, Stevenson SC. Transducer of regulated CREB-binding proteins (TORCs) induce PGC-1alpha transcription and mitochondrial biogenesis in muscle cells. Proc Natl Acad Sci U S A 2006;103:14379-14384.

40. Herzig S, Long F, Jhala US, Hedrick S, Quinn R, Bauer A, Rudolph D, Schutz G, Yoon C, Puigserver P, Spiegelman B, Montminy M. CREB regulates hepatic gluconeogenesis through the coactivator PGC-1. Nature 2001;413:179-183.

41. Gonzalez GA, Montminy MR. Cyclic AMP stimulates somatostatin gene transcription by phosphorylation of CREB at serine 133. Cell 1989;59:675-680.

42. Chen Y, Huang X, Zhang YW, Rockenstein E, Bu G, Golde TE, Masliah E, Xu H. Alzheimer's $\beta$ secretase (BACE1) regulates the cAMP/PKA/CREB pathway independently of $\beta$-amyloid. J Neurosci 2012;32:11390-11395.

43. Shoji S, Titani K, Demaille JG, Fischer EH. Sequence of two phosphorylated sites in the catalytic subunit of bovine cardiac muscle adenosine 3':5'-monophosphate-dependent protein kinase. J Biol Chem 1979;254:6211-6214.

44. Handschin C, Spiegelman BM. The role of exercise and PGC1alpha in inflammation and chronic disease. Nature 2008;454:463-469.

45. Handschin C. Peroxisome proliferator-activated receptor-gamma coactivator-1alpha in muscle links metabolism to inflammation. Clin Exp Pharmacol Physiol 2009;36:1139-1143.

46. Arnold AS, Egger A, Handschin C. PGC-1 $\alpha$ and myokines in the aging muscle - a mini-review. Gerontology 2011;57:37-43.

47. Zhang Y, Zhou B, Deng B, Zhang F, Wu J, Wang Y, Le Y, Zhai Q. Amyloid- $\beta$ induces hepatic insulin resistance in vivo via JAK2. Diabetes 2013;62:1159-66.

48. Wang R, Li JJ, Diao S, Kwak YD, Liu L, Zhi L, Büeler H, Bhat NR, Williams RW, Park EA, Liao FF. Metabolic stress modulates Alzheimer's $\beta$-secretase gene transcription via SIRT1-PPAR $\gamma$-PGC1 in neurons. Cell Metab 2013;17:685-694.

49. Tong L, Thornton PL, Balazs R, Cotman CW. Beta -amyloid-(1-42) impairs activity-dependent cAMP-response element-binding protein signaling in neurons at concentrations in which cell survival Is not compromised. J Biol Chem 2001;276:17301-17306

50. Koves, T.R., J.R. Ussher, R.C. Noland, D. Slentz, M. Mosedale, O. Ilkayeva, J. Bain, R. Stevens, J.R.B. Dyck, C.B. Newgard, G.D. Lopaschuk, D.M. Muoio. Mitochondrial overload and incomplete fatty acid oxidation contribute to skeletal muscle insulin resistance. Cell Metab 2008;7:45-56. 
51. Liang, H., B. Balas, P. Tantiwong, J. Dube, B.H. Goodpaster, R.M. O’Doherty, R.A. DeFronzo, A. Richardson, N. Musi, and W.F. Ward. Whole body overexpression of PGC-1alpha has opposite effects on hepatic and muscle insulin sensitivity. Am. Endocrinol. Metab. 2009; 296:E945-954. 


\section{Figure legends}

FIG. 1. Palmitate modulates Bace1 mRNA expression in myotubes. A, mRNA abundance of Bace1 from mouse $\mathrm{C} 2 \mathrm{C} 12$ myotubes incubated in the presence or absence (Ct: control, white bars) of $0.5 \mathrm{mM}$ palmitate (Pal, black bars) for different times. The graphs show quantification of the aprt-normalized mRNA levels, expressed as a percentage of control samples \pm SD of six independent experiments. B, Bace1 mRNA levels in mouse $\mathrm{C} 2 \mathrm{C} 12$ myotubes incubated in the presence or absence (Ct: control) of $0.5 \mathrm{mM}$ palmitate (Pal) or $0.5 \mathrm{mM}$ palmitate plus $10 \mu \mathrm{M}$ parthenolide (Parth) for $8 \mathrm{~h}$. Data are means samples $\pm \mathrm{SD}$ of six independent experiments. $\mathbf{C}$, Cell lysates from $\mathrm{C} 2 \mathrm{C} 12$ myotubes incubated in the presence or absence $(\mathrm{Ct}$ : control) of $0.5 \mathrm{mM}$ palmitate (Pal) for 8 and $16 \mathrm{~h}$ were assayed for Western-blot analysis with antibodies against BACE1 and $\beta$-actin. The graphs show quantification of normalized protein levels expressed as a percentage of control samples \pm SD of four independent experiments. Skeletal muscle and white adipose tissue from male mice fed a standard diet (Control, CT) or a high-fat diet (HFD) ( $\mathrm{n}=5$ per group) for 12 weeks. mRNA abundance (D) and protein levels (E) of BACE1 in skeletal muscle. mRNA abundance (F) and protein levels $(\mathbf{G})$ of BACE1 in white adipose tissue. ${ }^{* * *} \mathrm{p}<0.001, * * \mathrm{p}<0.01$ and $* \mathrm{p}<0.05$ vs. control. $\#$ \# $<0.001$ vs. palmitate-exposed cells.

FIG. 2. BACE1 inhibition attenuates palmitate-induced ER stress, inflammation, and insulin resistance in myotubes. Mouse $\mathrm{C} 2 \mathrm{C} 12$ myotubes were incubated in the presence or absence (Ct: control) of $0.5 \mathrm{mM}$ palmitate (Pal) or palmitate $0.5 \mathrm{mM}$ plus $100 \mathrm{nM}$ Merck 3 (M3) for $16 \mathrm{~h}$. A, spliced Xbp1 (sXbp1) mRNA levels. uXBP1, unspliced XBP1. B, Atf3, Chop, Tnf- $\alpha$, Il-6, and BiP mRNA levels. The graphs show quantification of aprt-normalized mRNA levels, expressed as a percentage of control samples \pm SD of six independent experiments. C, Cell lysates were subjected to Western blot analysis with antibodies against I $\mathrm{B} \alpha$ and $\mathrm{p} 65$. The graphs show quantification of normalized protein levels expressed as a percentage of control samples \pm SD of four independent experiments. D, Autoradiograph of EMSA performed with a ${ }^{32} \mathrm{P}-$ labeled NF- $\kappa B$ nucleotide and crude nuclear protein extract (NE) from $\mathrm{C} 2 \mathrm{C} 12$ myotubes. Two main specific complexes (I and II) based on competition with a molar excess of unlabeled probe are shown. The 
supershift immune complex (IC) obtained by incubating NE with an antibody (Ab) directed against the p65

subunit of NF- $\mathrm{kB}$ is also shown. Competition and supershift studies demonstrated that band I was specific and mainly consisted of the p65 subunit of NF-кB. Cell lysates were subjected to Western blot analysis with antibodies against IR $\beta$, phospho-IRS1 $\left(\mathrm{Ser}^{307}\right)(\mathbf{E})$ and total and phospho-Akt $\left(\mathrm{Ser}^{473}\right)(\mathbf{F})$. Where indicated, cells were incubated with $100 \mathrm{nM}$ insulin (Ins) for the last $10 \mathrm{~min}$. The graphs show quantification of normalized protein levels expressed as a percentage of control samples \pm SD of four independent experiments. G, Pgc- $1 \alpha$, Ppar $\alpha$ and $\operatorname{Ppar} \beta / \delta$ mRNA levels. The graphs show quantification of aprt-normalized mRNA levels, expressed as a percentage of control samples \pm SD of six independent experiments. H, PGC- $1 \alpha$, PPAR $\alpha$ and PPAR $\beta / \delta$ protein levels. I, I $\kappa B \alpha$, Acox, Mcad and Cpt- $1 \alpha$ mRNA levels (n=6). J, Autoradiograph of EMSA performed with a ${ }^{32}$ P-labeled PPRE nucleotide and crude nuclear protein extract (NE) from $\mathrm{C} 2 \mathrm{C} 12$ myotubes. Two main specific complexes (I and II) based on competition with a molar excess of unlabeled probe are shown. The supershift immune complex (IC) obtained by incubating NE with an antibody (Ab) directed against PPAR $\alpha$ is also shown. PPRE, Peroxisome proliferator response element. ${ }^{* * *} \mathrm{p}<0.001,{ }^{*} \mathrm{p}<0.01$ and ${ }^{*} \mathrm{p}<0.05$ vs. control, ${ }^{\# \#} \mathrm{p}<0.001,{ }^{\# \#} \mathrm{p}<0.01$ and ${ }^{\#} \mathrm{p}<0.05$ vs. palmitate-exposed cells. ${ }^{\dagger} \mathrm{p}<0.05$ vs. control cells incubated with insulin.

FIG. 3. BACE1 deficiency increases PGC-1 $\alpha$ levels. C2C12 cells were transfected with control or BACE1 siRNA for 24 hours and the expression (A) and protein levels (B) of PGC-1 $\alpha$, PPAR $\alpha$ and PPAR $\beta / \delta$ were examined (n=4). C, Chop, Tnf- $\alpha$, Mcp-1, Cpt- $1 \alpha$, Acox and Mcad mRNA levels in C2C12 cells transfected with control or BACE1 siRNA for 24 hours $(n=5)$. D, Cell lysates from $\mathrm{C} 2 \mathrm{C} 12$ cells transfected with control or BACE1 siRNA for 24 hours were subjected to Western blot analysis with antibodies against I $\mathrm{B} \alpha \alpha$ and IR $\beta$ and phospho-IRS1 $\left(\mathrm{Ser}^{307}\right)$. The graphs show quantification of normalized protein levels expressed as a percentage of control samples \pm SD of four independent experiments. *** $\mathrm{p}<0.001$, ** $p<0.01$ and $* \mathrm{p}<0.05$ vs. control. Skeletal muscle from Bace1-deficient mice show increased expression and protein levels of genes involved in FA metabolism, inflammation and insulin signaling. Skeletal 
muscle from male wild-type and BACE1-null mice was used (n=6 per group). mRNA abundance (E) and protein levels $(\mathbf{F})$ of PGC-1 $\alpha$, PPAR $\alpha$ and PPAR $\beta / \delta$. G, mRNA levels of I $\kappa \mathrm{B} \alpha$, Mcp-1, Tnf- $\alpha$, Chop, Cpt$1 \alpha$, Acox and Mcad. The graphs show quantification of aprt-normalized mRNA levels, expressed as a percentage of control samples \pm SD of six independent experiments. H, Cell lysates from wild-type and BACE1-null mice were subjected to Western blot analysis with antibodies against $\mathrm{I} \kappa \mathrm{B} \alpha$, total and phospho-eIF2 $\alpha$, IR $\beta$ and phospho-IRS1 $\left(\mathrm{Ser}^{307}\right)$. The graphs show quantification of normalized protein levels expressed as a percentage of control samples $\pm \mathrm{SD}(\mathrm{n}=5) . * * * \mathrm{p}<0.001, * * \mathrm{p}<0.01$ and ${ }^{*} \mathrm{p}<0.05$ vs. control. I, Bace1 knockdown prevents the reduction in Pgc-1 $\alpha$ expression caused by an HFD in skeletal muscle. Skeletal muscle from wild-type and BACE1-null mice fed with a regular chow diet and HFD for 20 weeks. mRNA abundance of $\operatorname{Pgc}-1 \alpha, \operatorname{Ppar} \alpha, \operatorname{I} \kappa b \alpha, \operatorname{Tnf}-\alpha$ and Il-6. The graphs show quantification of aprt-normalized mRNA levels, expressed as a percentage of control samples $\pm \mathrm{SD}(\mathrm{n}=5)$. *** $\mathrm{p}<0.001$, ${ }^{* *} \mathrm{p}<0.01$ and ${ }^{*} \mathrm{p}<0.05$ vs. wild-type mice fed a regular chow diet, ${ }^{\# \#} \mathrm{p}<0.001$ and ${ }^{\# \#} \mathrm{p}<0.01$ and vs. wildtype mice fed an HFD.

FIG. 4. sAPP $\beta$ mimics the effects of palmitate exposure on ER stress, inflammation, and insulin resistance. Mouse $\mathrm{C} 2 \mathrm{C} 12$ myotubes were incubated in the presence or absence (Ct: control) of $0.5 \mathrm{mM}$ palmitate (Pal) for $16 \mathrm{~h}$ or $20 \mathrm{nM}$ sAPP $\beta$ for 24 plus $16 \mathrm{~h}$. A, Pgc- $1 \alpha$, Ppar $\alpha$, Ppar $\beta / \delta$, Cpt- $1 \alpha$, Acox and Mcad mRNA levels. The graphs show quantification of aprt-normalized mRNA levels, expressed as a percentage of control samples \pm SD of six independent experiments. Cell lysates were subjected to Western blot analysis with antibodies against (PGC-1 $\alpha)($ B) or different members of the OXPHOS complexes (n=4) (C). D, Atf3, Chop, Tnf- $\alpha$, Il-6 and I $\kappa \mathrm{B} \alpha$ mRNA levels. Cell lysates were subjected to Western blot analysis with antibody against the p65 subunit of NF-kB (E), IR $\beta(\mathbf{F})$, phospho-IRS1 $\left(\operatorname{Ser}^{307}\right)$ (G) and phospho-Akt $\left(\operatorname{Ser}^{473}\right)(\mathbf{H})(\mathrm{n}=4)$. Where indicated, cells were incubated with $100 \mathrm{nM}$ insulin (Ins) for the last $10 \mathrm{~min}$. The graphs show quantification of normalized protein levels expressed as a percentage of control samples \pm SD of four independent experiments. I, 2-DG uptake was assessed without or with insulin (n=6). cells were incubated with $20 \mathrm{nM}$ sAPP $\beta$ or sAPP $\alpha$ for 24 plus $16 \mathrm{~h}$. ${ }^{*} \mathrm{p}<0.05$ vs. control. 
${ }^{\# \#} \mathrm{p}<0.001$ vs. insulin-stimulated cells. J, BACE1 inhibition and sAPP $\beta$ regulate FAO oxidation (FAO) in $\mathrm{C} 2 \mathrm{C} 12$ myotubes. Total FAO rate represented as the sum of acid-soluble products plus $\mathrm{CO}_{2}$ oxidation. Mouse $\mathrm{C} 2 \mathrm{C} 12$ myotubes were incubated in the presence or absence $(\mathrm{Ct}$ : control) of $0.5 \mathrm{mM}$ palmitate (Pal), incubated with $100 \mathrm{nM}$ Merck 3 alone for 24 plus $16 \mathrm{~h}$ (M3), pre-incubated with Merck3 for $24 \mathrm{~h}$ and then incubated with palmitate $0.5 \mathrm{mM}$ plus $100 \mathrm{nM}$ Merck3 for $16 \mathrm{~h}(\mathrm{Pal}+\mathrm{M} 3)$ or cells were incubated with $20 \mathrm{nM}$ sAPP $\beta$ for 24 plus $16 \mathrm{~h}(\mathrm{n}=4) .{ }^{* * *} \mathrm{p}<0.001,{ }^{*} \mathrm{p}<0.01$ and $* \mathrm{p}<0.05$ vs. control. ${ }^{\# \#} \mathrm{p}<0.001$, $\# \#$ p $<0.01$ and ${ }^{\#} \mathrm{p}<0.05$ vs. palmitate-exposed cells, ${ }^{\dagger \dagger} \mathrm{p}<0.001$ vs. control cells incubated with insulin.

FIG. 5. Increased BACE1 expression in subcutaneous adipose tissue is accompanied by enhanced plasma levels of sAPP $\beta$ in type 2 diabetic subjects. A, qRT-PCR analysis of BACE1 and PGC- $1 \alpha$ in subcutaneous adipose tissue of lean $(n=18)$, obese $(n=21)$ and type 2 diabetic patients (T2D) $(n=23)$. The mRNA expression of each gene was normalized to GAPDH. Values are reported as mean \pm SEM. B, sAPP $\beta$ and $\mathrm{A} \beta 42$ in the plasma of mice fed a control diet (Ct, white bars) or a HFD (black bars) for 3 weeks. Ponceau $\mathrm{S}$ staining served as loading controls. $* * * \mathrm{p}<0.001$ vs. mice fed a regular diet. Representative images of plasma sAPP $\beta$ levels in obese and lean subjects (C) and type 2 diabetic (T2D) and obese subjects (D). Ponceau S staining served as loading controls. ${ }^{*} \mathrm{p}<0.05$ vs. obese subjects. Intramuscular (i.m.) injection of sAPP $\beta$ in the gastrocnemius muscle of mice reduces PGC- $1 \alpha$ levels. E, Chop, Atf3, BiP, Tnf- $\alpha$, and Il-6 mRNA levels. F, Pgc-1a, and Ppar $\alpha$ mRNA abundance. The graphs show quantification of aprtnormalized mRNA levels, expressed as a percentage of control samples $\pm \mathrm{SD}$ ( $\mathrm{n}=6$ per group). G, Protein extracts from gastrocnemius muscle of mice treated with sAPP $\beta$ (i.m.injection) or vehicle were subjected to Western blot analysis with antibodies against PGC-1 $\alpha$, BiP, total and phospho-eIF2 $\alpha$ and IкB $\alpha$. The graphs show quantification of normalized protein levels expressed as a percentage of control samples \pm SD (n=6 per group). $* * * \mathrm{p}<0.001, * * \mathrm{p}<0.01$ and $* \mathrm{p}<0.05$ vs. control mice treated with vehicle. 
FIG. 6. sAPP $\beta$ administration to mice reduces PGC-1 $\alpha$ in skeletal muscle and liver, reduces insulin sensitivity and lowers basal glucose levels. sAPP $\beta$ or vehicle was administered to mice (i.p.) (10 $\mu \mathrm{g} /$ mouse) before $(20.00 \mathrm{~h})$ and after $(8.00 \mathrm{~h})$ an overnight fasting to conduct either a GTT or a ITT. A, plasma basal glucose levels 6 hours later the last administration of sAPP $\beta$ ( $n=6$ per group). B, GTT and ITT and area under the curve (AUC). Data are presented as the mean \pm S.D. ( $n=6$ per group). C, Atf3, BiP, Chop, Tnf- $\alpha$, and IL-6 mRNA levels in skeletal muscle from mice treated with vehicle or sAPP $\beta$. The graphs show quantification of aprt-normalized mRNA levels, expressed as a percentage of control samples $\pm \mathrm{SD}$ ( $\mathrm{n}=6$ per group). $\mathrm{D}, \mathrm{I} \kappa \mathrm{B} \alpha$ and $\mathrm{BiP}$ protein levels in skeletal muscle from mice treated with vehicle or sAPP $\beta$ (n=5 per group). E, Pgc-1a, and Ppar $\alpha$ mRNA abundance. PGC-1 $\alpha$, phospho-CREB (Ser ${ }^{133}$ ), phospho-PKA $\left(\mathrm{Thr}^{197}\right)(\mathbf{F})$, IR $\beta$, and phospho-IRS1 $\left(\operatorname{Ser}^{307}\right)(\mathbf{G})$ protein levels in skeletal muscle from mice treated with vehicle or $\operatorname{sAPP} \beta$ (n=5 per group). H, Pgc- $1 \alpha$, Ppar $\alpha, I \kappa B \alpha$, Atf3, BiP, Chop Tnf- $\alpha$, IL-6, Pepck, and G6Pase mRNA abundance in liver from mice treated with vehicle or sAPP $\beta$ ( $\mathrm{n}=6$ per group). I, PGC-1 $\alpha$ and NRF-1 protein levels in liver from mice treated with vehicle or sAPP $\beta$ ( $n=5$ per group). $\mathbf{J}$, IR $\beta$, and phospho-IRS1 $\left(\operatorname{Ser}^{307}\right)$ protein levels in liver from mice treated with vehicle or sAPP $\beta(n=5$ per group). K, Pyruvate tolerance test and AUC ( $\mathrm{n}=4$ per group). $* * * \mathrm{p}<0.001, * * \mathrm{p}<0.01$ and $* \mathrm{p}<0.05$ vs. control.

FIG. 7. BACE1 regulates the cAMP-PKA-CREB pathway in myotubes. Mouse C2C12 myotubes were incubated in the presence or absence (Ct: control) of $0.5 \mathrm{mM}$ palmitate (Pal) or pre-incubated with $100 \mathrm{nM}$ Merck 3 (M3) for $24 \mathrm{~h}$ and then incubated with palmitate $0.5 \mathrm{mM}$ plus $100 \mathrm{nM} \mathrm{M} 3$ for $16 \mathrm{~h}$ or cells were incubated with $20 \mathrm{nM}$ sAPP $\beta$ for $40 \mathrm{~h}$. A, B, Cell lysates were subjected to Western blot analysis with antibodies against total and phospho-CREB $\left(\mathrm{Ser}^{133}\right)$. Phospho-CREB $\left(\mathrm{Ser}^{133}\right)$ protein levels in $\mathrm{C} 2 \mathrm{C} 12$ cells transfected with control or BACE1 siRNA for 24 hours (C) or in skeletal muscle from wild-type and Bace1-deficient mice (D) ( $\mathrm{n}=4-6$ per group). Phospho-PKA $\left(\mathrm{Thr}^{197}\right.$ ) protein levels in $\mathrm{C} 2 \mathrm{C} 12$ myotubes exposed to palmitate or palmitate plus M3 (E) or exposed to sAPP $\beta(\mathbf{F})$ (n=4-6 per group). Phospho-PKA 
$\left(\mathrm{Thr}^{197}\right.$ ) protein levels in $\mathrm{C} 2 \mathrm{C} 12$ cells transfected with control or BACE1 siRNA for $24 \mathrm{~h}(\mathbf{G})$ or in skeletal muscle from wild-type and Bace1-deficient mice $(\mathbf{H})$. The graphs show quantification of normalized protein levels expressed as a percentage of control samples \pm SD (n=4-6 per group). PKA activity (I) and cAMP levels $(\mathbf{J})(\mathrm{n}=5)$. K, C2C12 protein extracts were immunoprecipitated using an adenylate cyclase antibody and then subjected to SDS-PAGE and immunoblotted with an anti-BACE1 antibody. No immunoprecipitation was observed with the unrelated antibody OCT1, indicating that the effect of the antiBACE1 antibody was specific. ${ }^{* * *} \mathrm{p}<0.001,{ }^{*} \mathrm{p}<0.01$ and $* \mathrm{p}<0.05$ vs. control, ${ }^{\# \#} \mathrm{p}<0.001,{ }^{\# \#} \mathrm{p}<0.01$ and ${ }^{\#} \mathrm{p}<0.05$ vs. palmitate-exposed cells.

FIG. 8. sAPP $\beta$ increases BACE1 levels and its interaction with AC. A, BACE1 protein levels in skeletal muscle from mice treated with vehicle or sAPP $\beta$ (i.p.) $(10 \mu \mathrm{g} /$ mouse) twice in a day. PGC-1 $\alpha$ and BACE1 mRNA (B) and protein $(\mathbf{C})$ levels in mouse $\mathrm{C} 2 \mathrm{C} 12$ myotubes incubated in the presence or absence $(\mathrm{Ct}$ : control) of $20 \mathrm{nM}$ sAPP $\beta$ for 24 plus $16 \mathrm{~h}$ or $20 \mathrm{nM}$ sAPP $\beta$ plus $10 \mu \mathrm{M}$ parthenolide (Parth). The graphs show quantification of the aprt-normalized mRNA levels, expressed as a percentage of control samples \pm SD of six independent experiments. ${ }^{* * *} \mathrm{p}<0.001$ vs. control. ${ }^{\# \#} \mathrm{p}<0.001$ vs. sAPP $\beta$-exposed cells. C2C12 myotubes (D) and skeletal muscle from mice treated with vehicle or sAPP $\beta$ (E) protein extracts were immunoprecipitated using an adenylate cyclase antibody and then subjected to SDS-PAGE and immunoblotted with an anti-BACE1 antibody. No immunoprecipitation was observed with the unrelated antibody OCT1, indicating that the effect of the anti-BACE1 antibody was specific. F, Proposed mechanism by which the lipid-induced increase in BACE1 and sAPP $\beta$ reduce PGC- $1 \alpha$ and exacerbates lipid-induced ER stress, inflammation and insulin resistance in skeletal muscle and reduce gluconeogenesis in liver. 
A

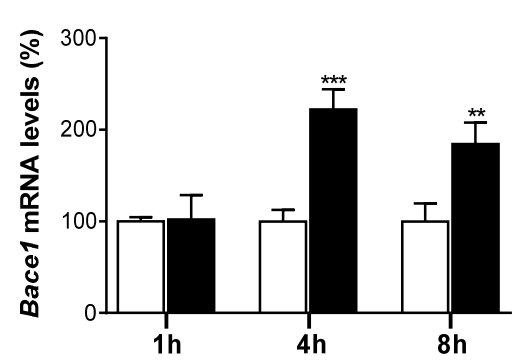

C

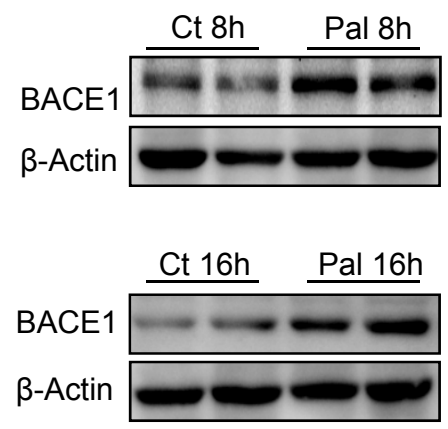

D

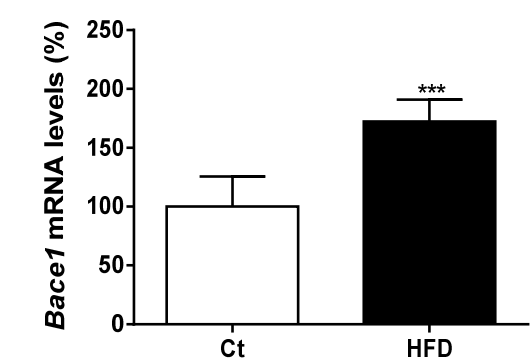

$\mathrm{F}$

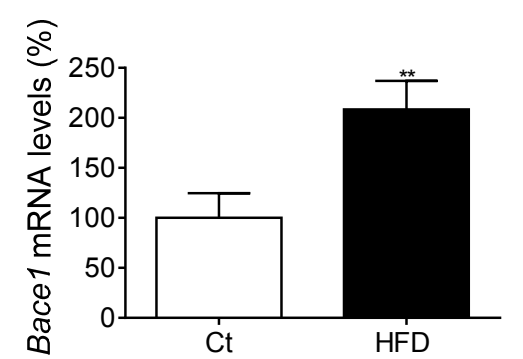

B
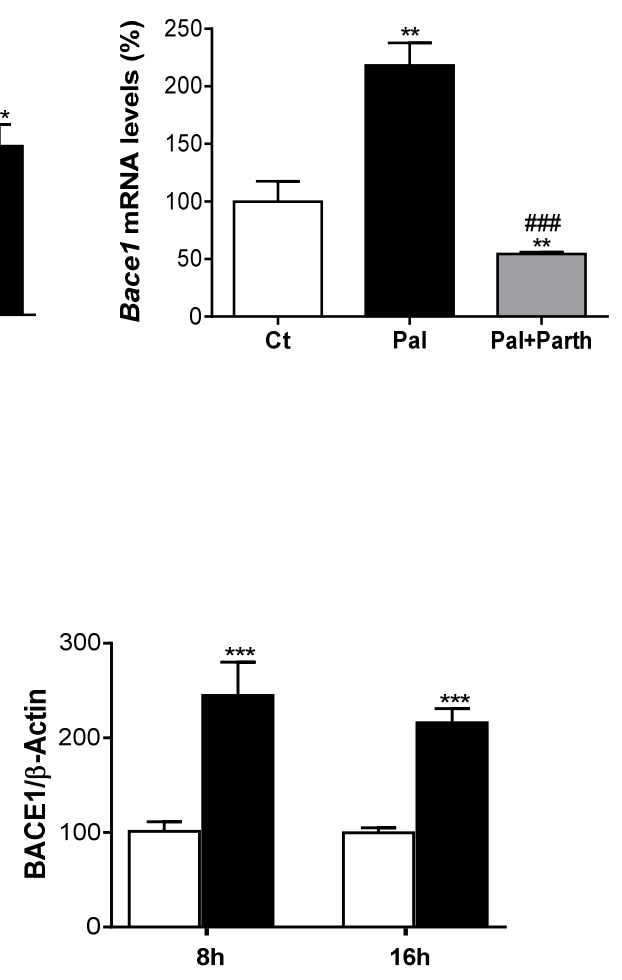

E

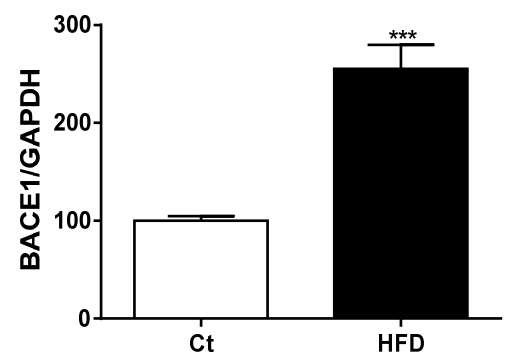

G

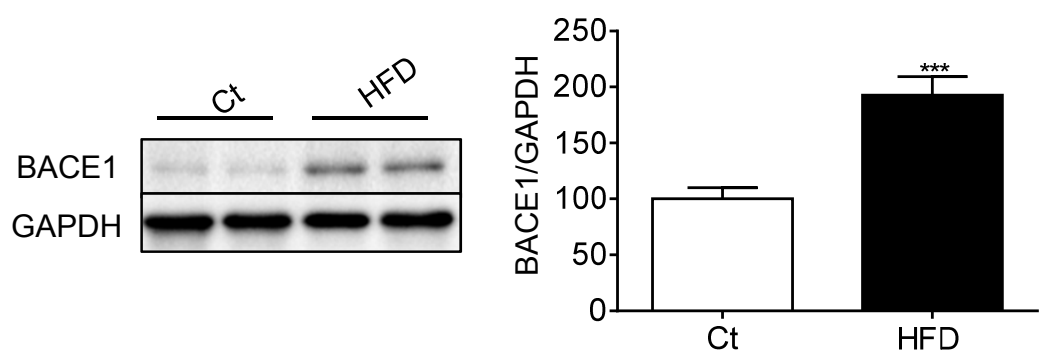



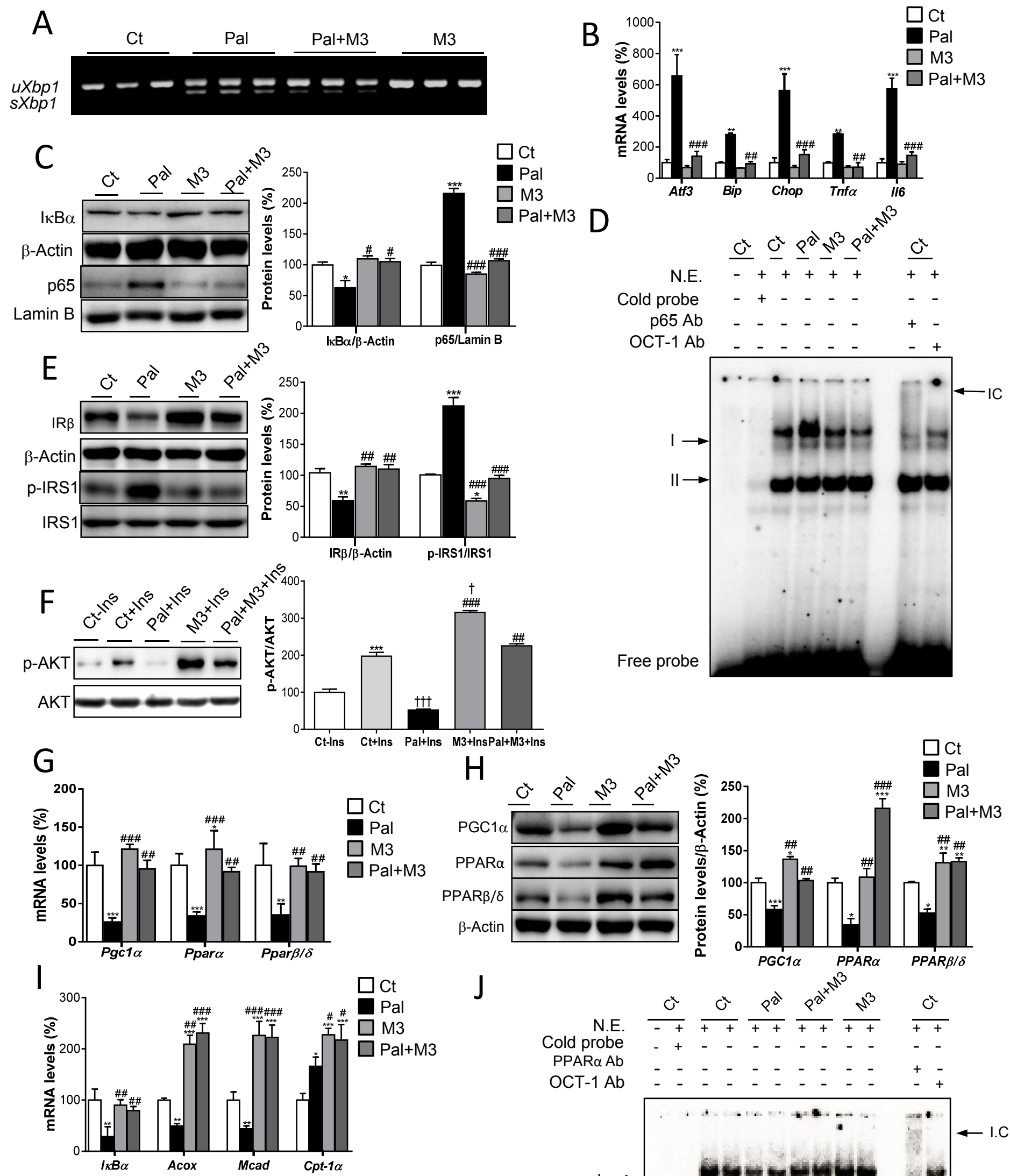

J

Figure 2

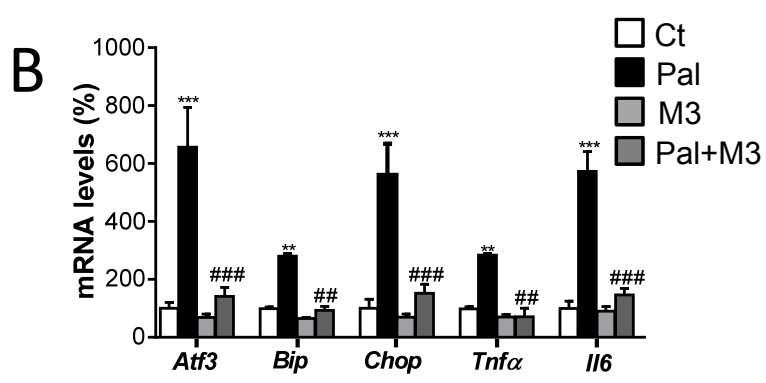

D

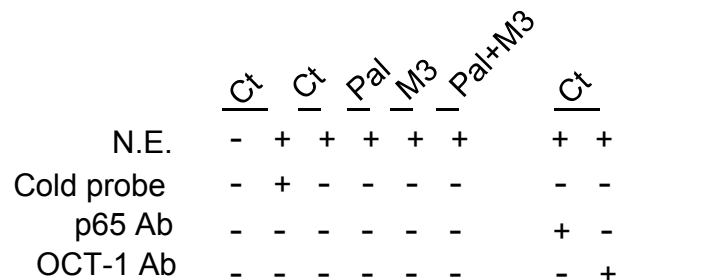

Free probe

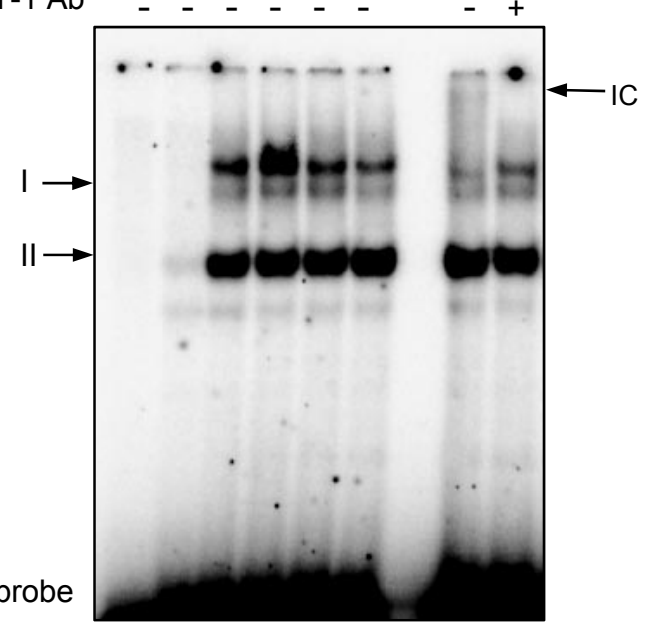


A

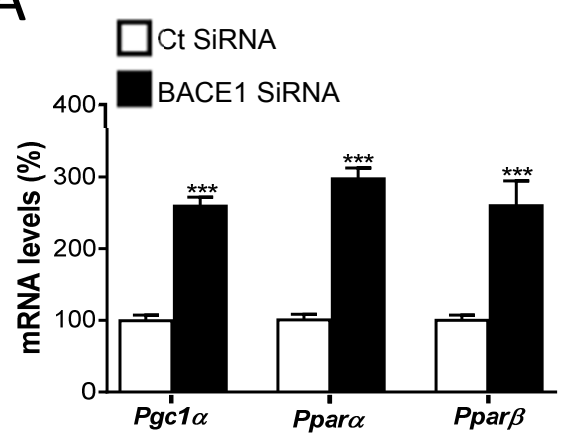

C

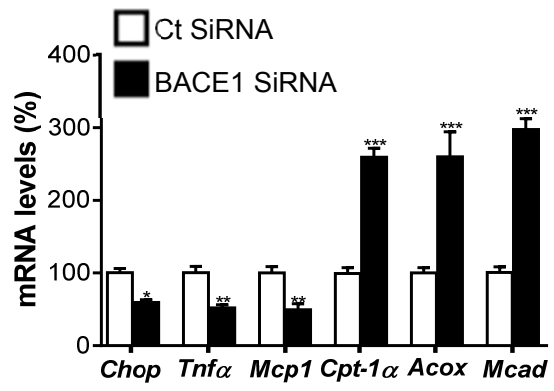

E

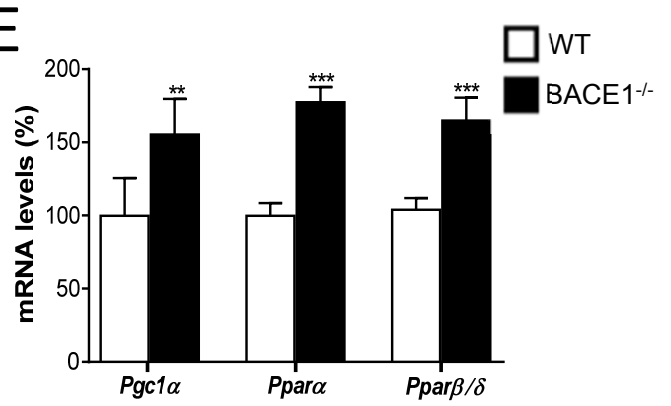

G
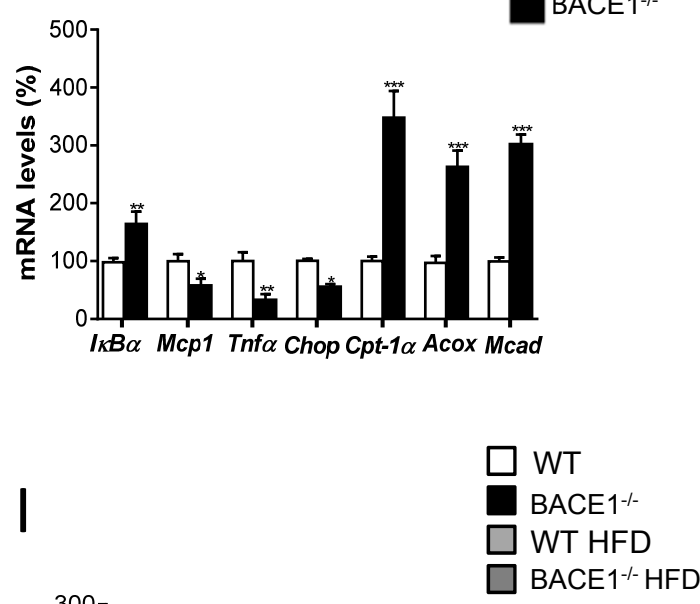

B
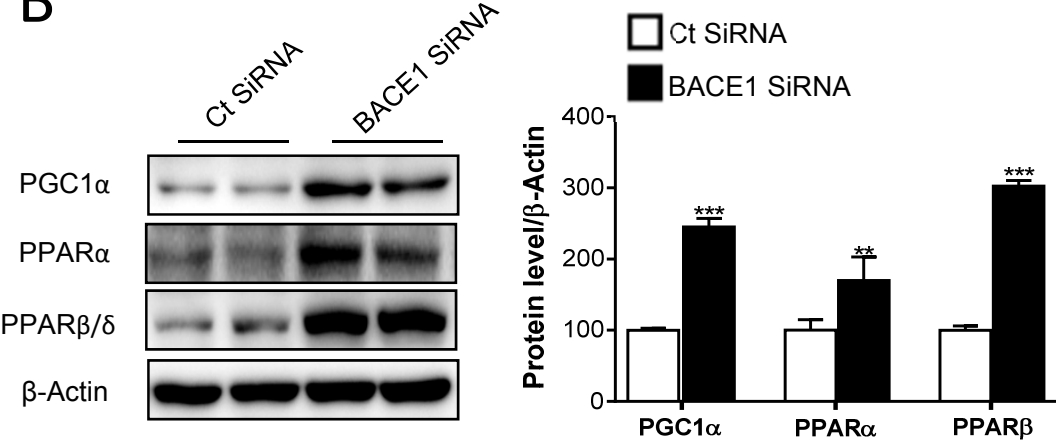

D

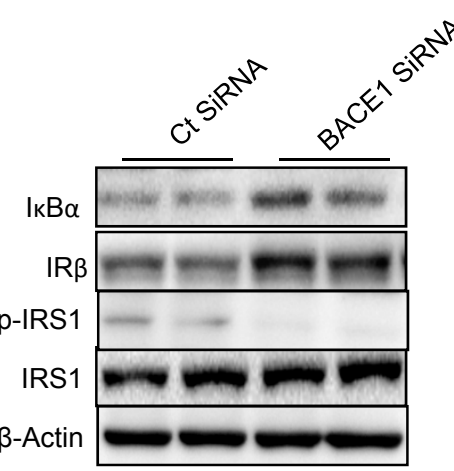

$\square$ Ct SiRNA

BACE1 SiRnA

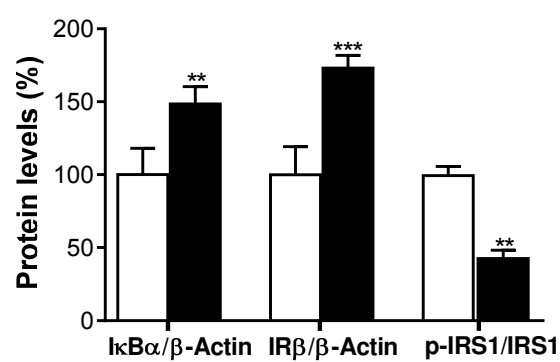

F

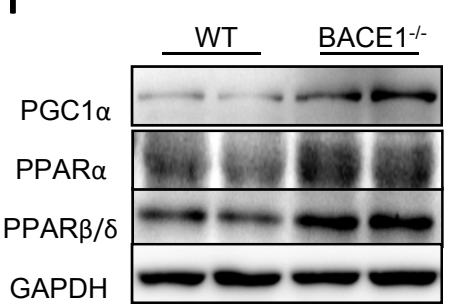

${ }^{250}{ }^{250} \quad \square$ WT

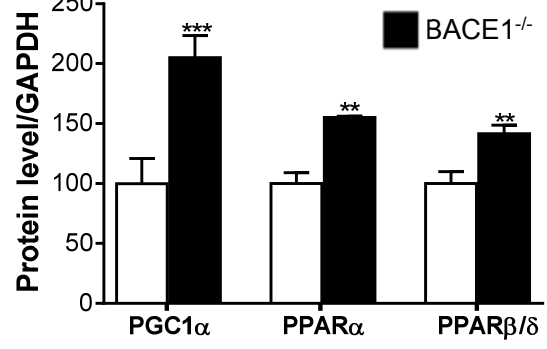

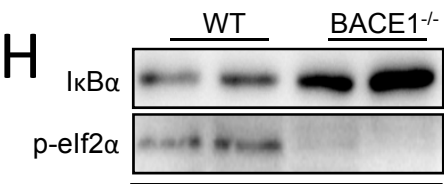
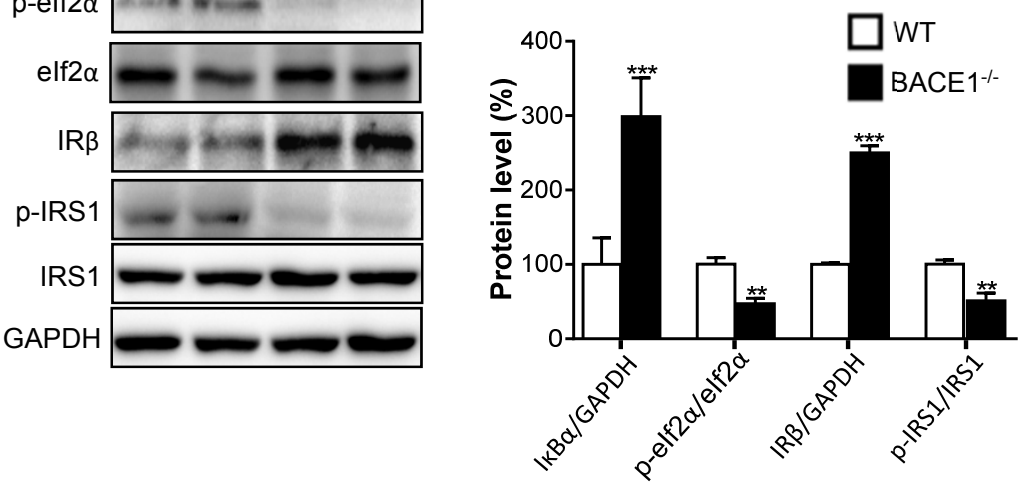

Figure 3 
A

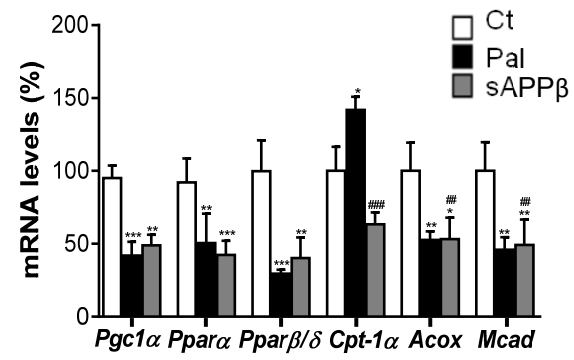

C

Complex I

Complex II

Complex III

Complex IV

Complex V

Prohibitin

$\beta$-Actin
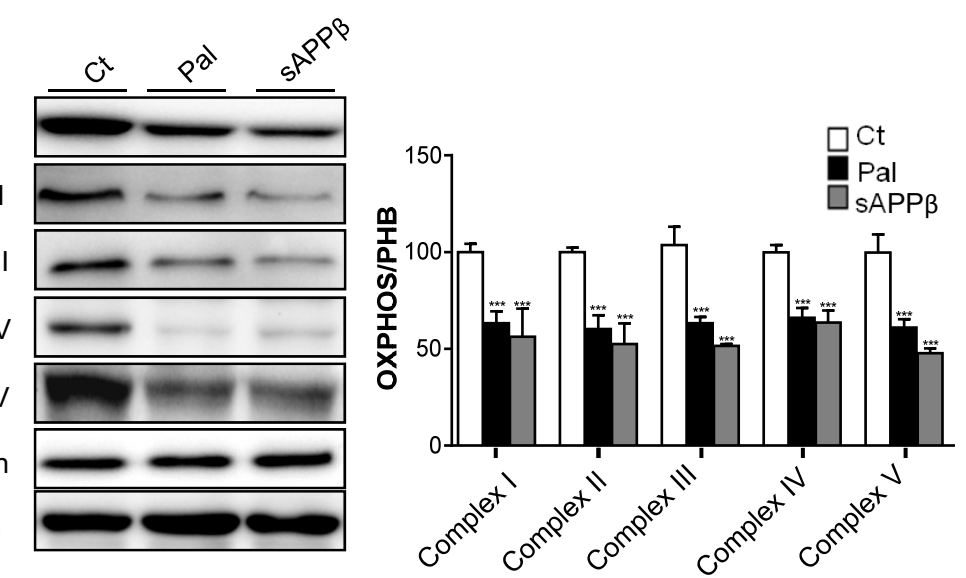

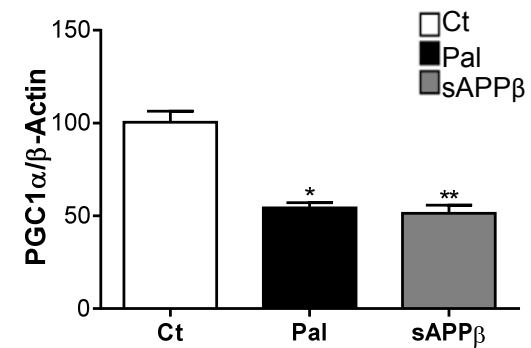

D
$\beta$-Actin

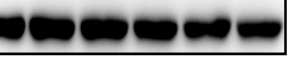

E

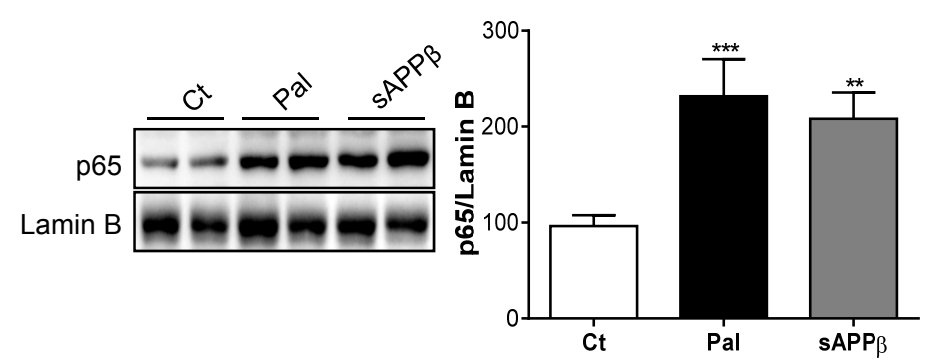

F

G
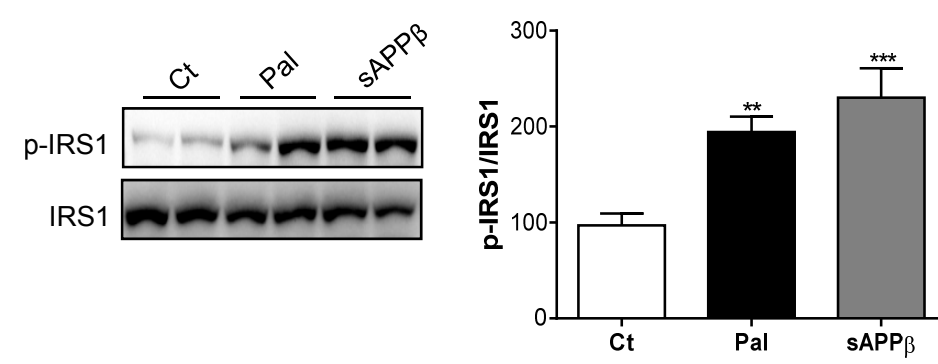
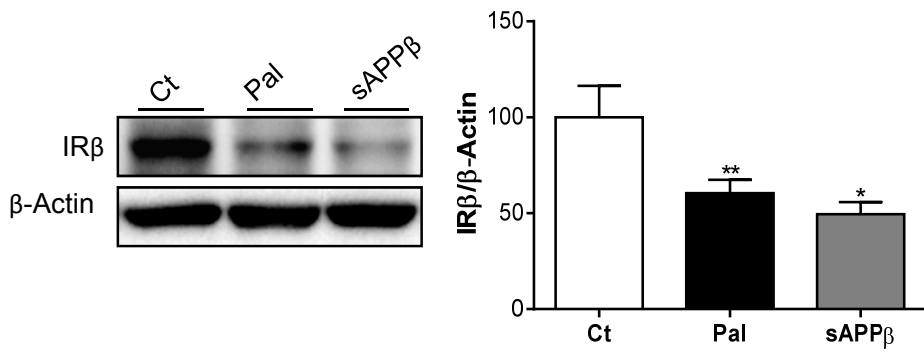

$\mathrm{H}$

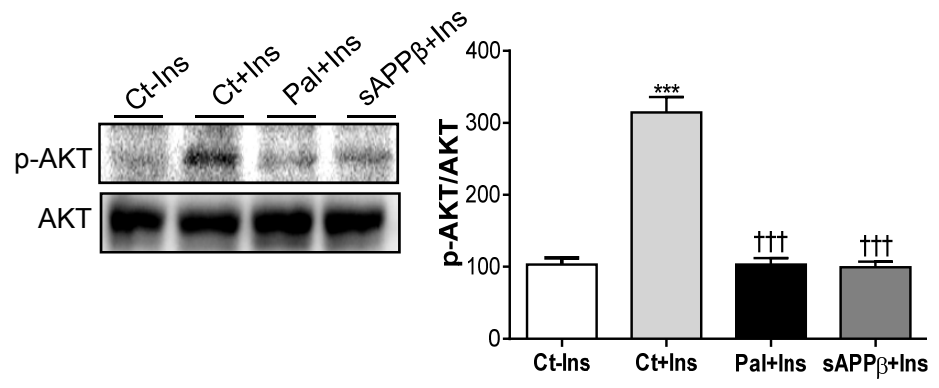

J
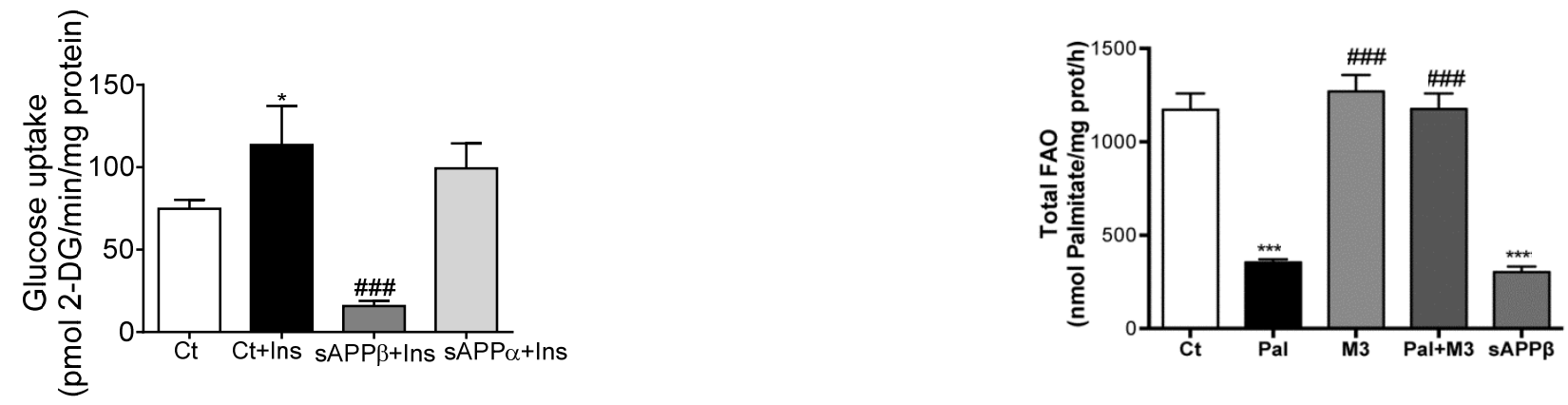

Figure 4 
A

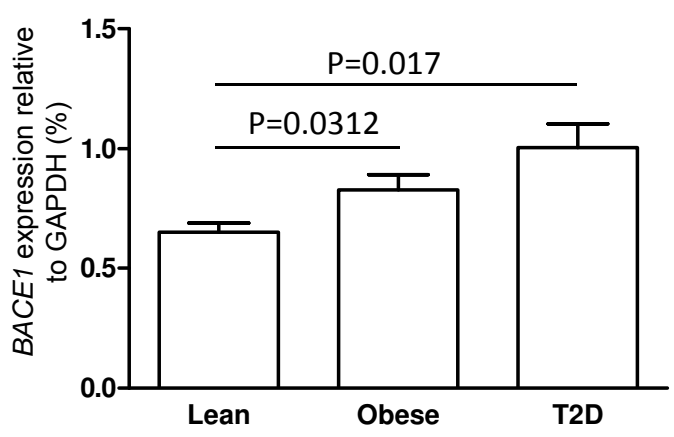

B

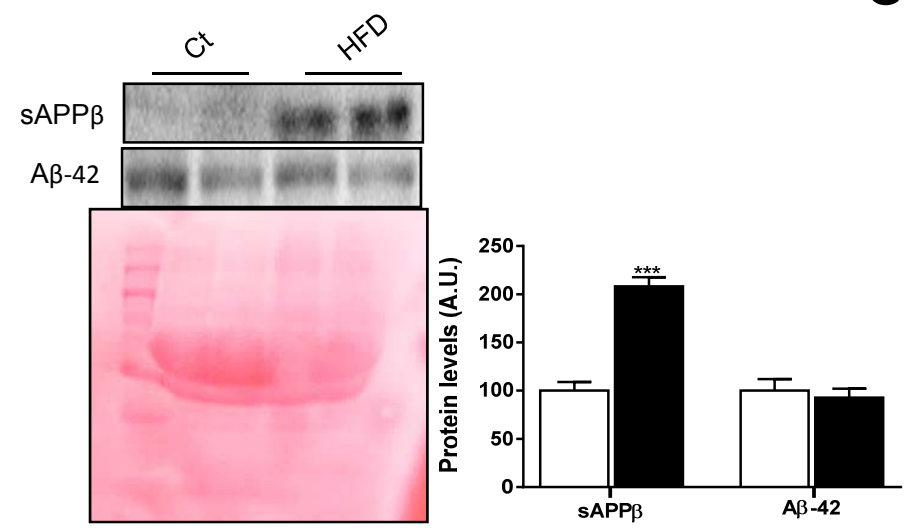

D

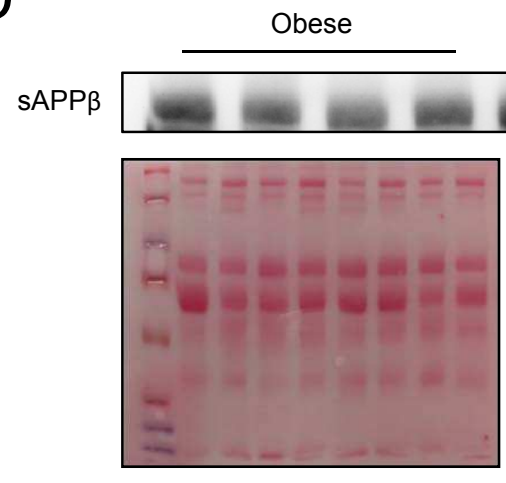

T2D

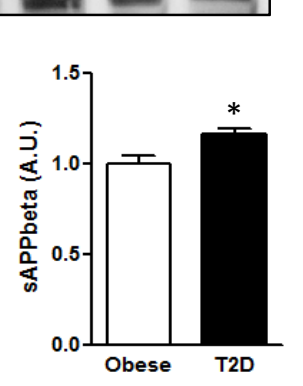

F

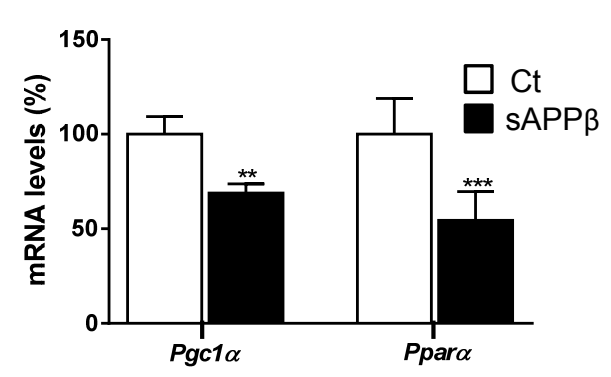

G

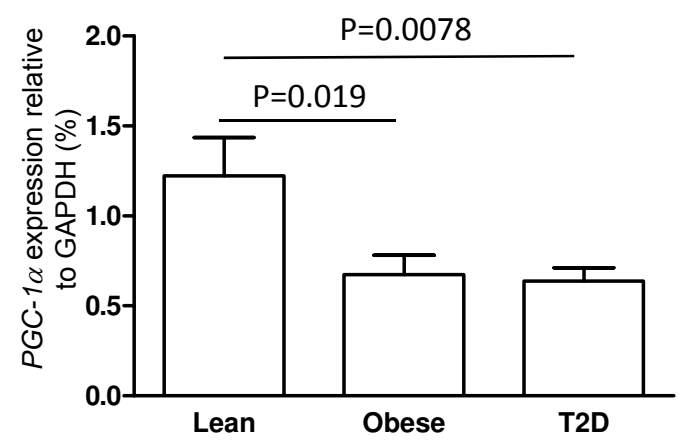

C
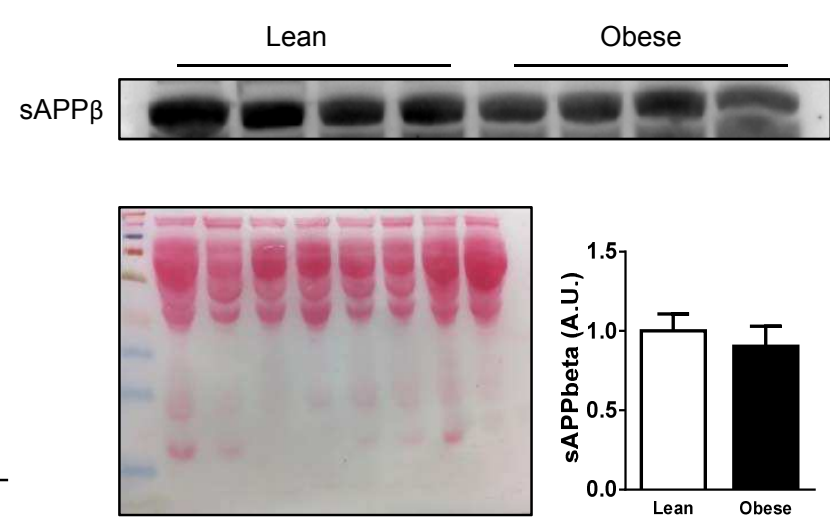

E

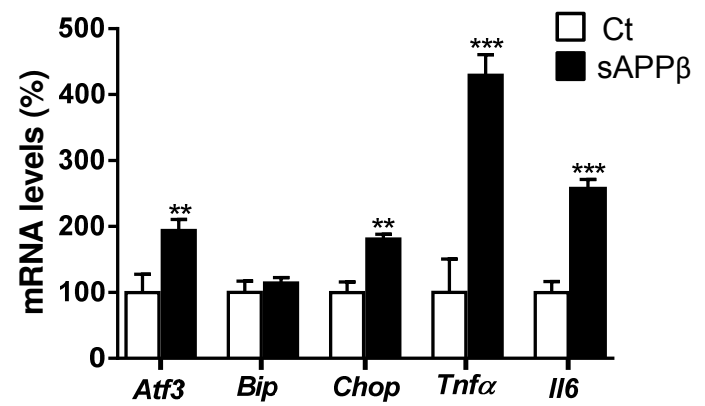

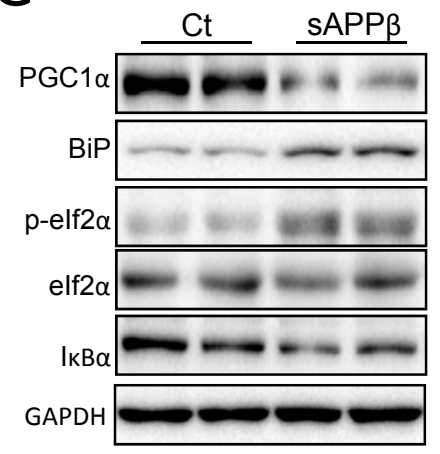

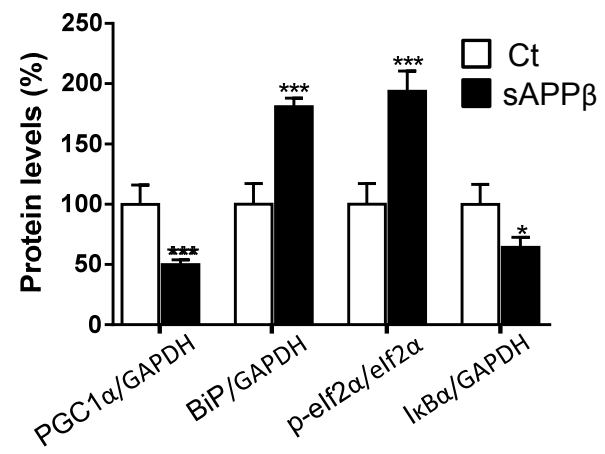

Figure 5 
A

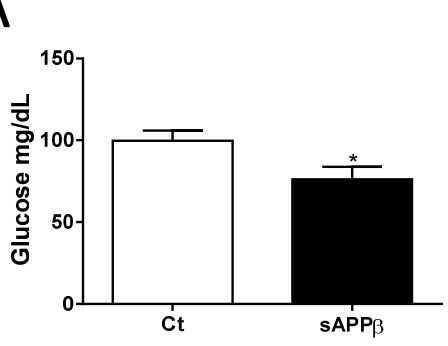

C

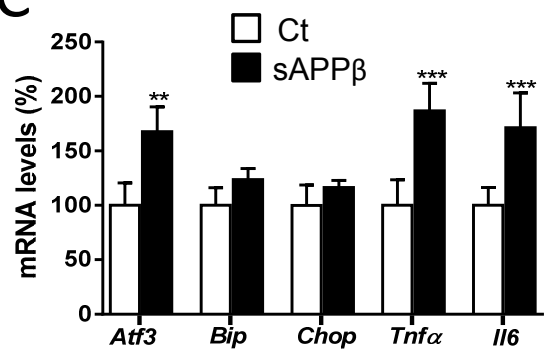

E

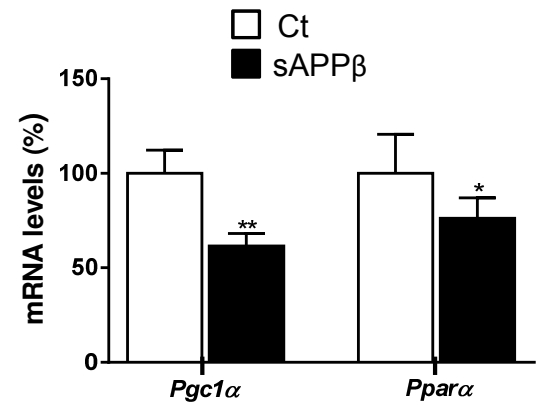

G

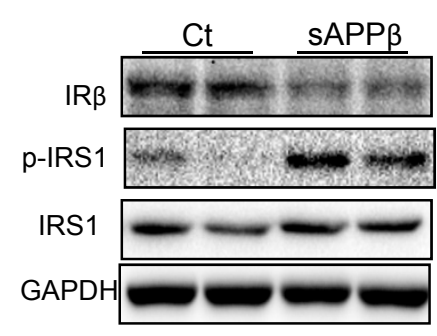

Liver

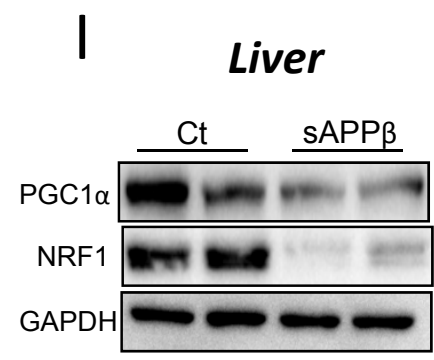

K

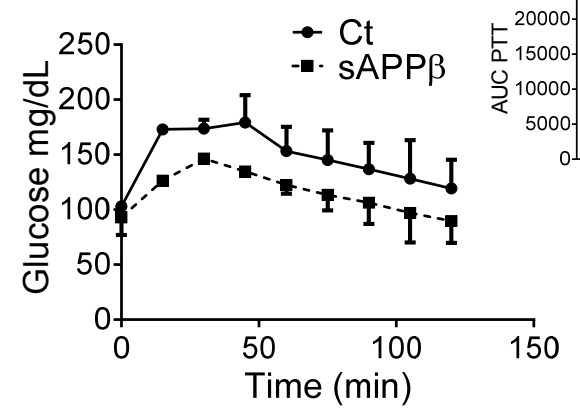

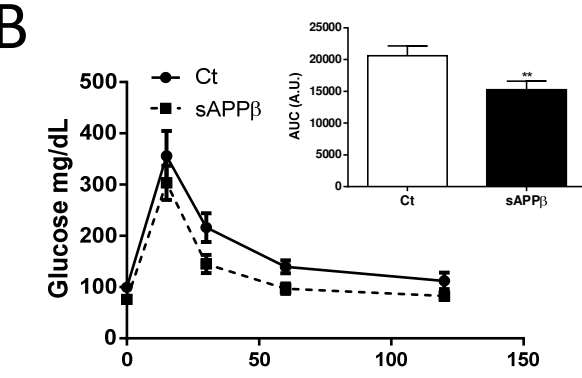

D
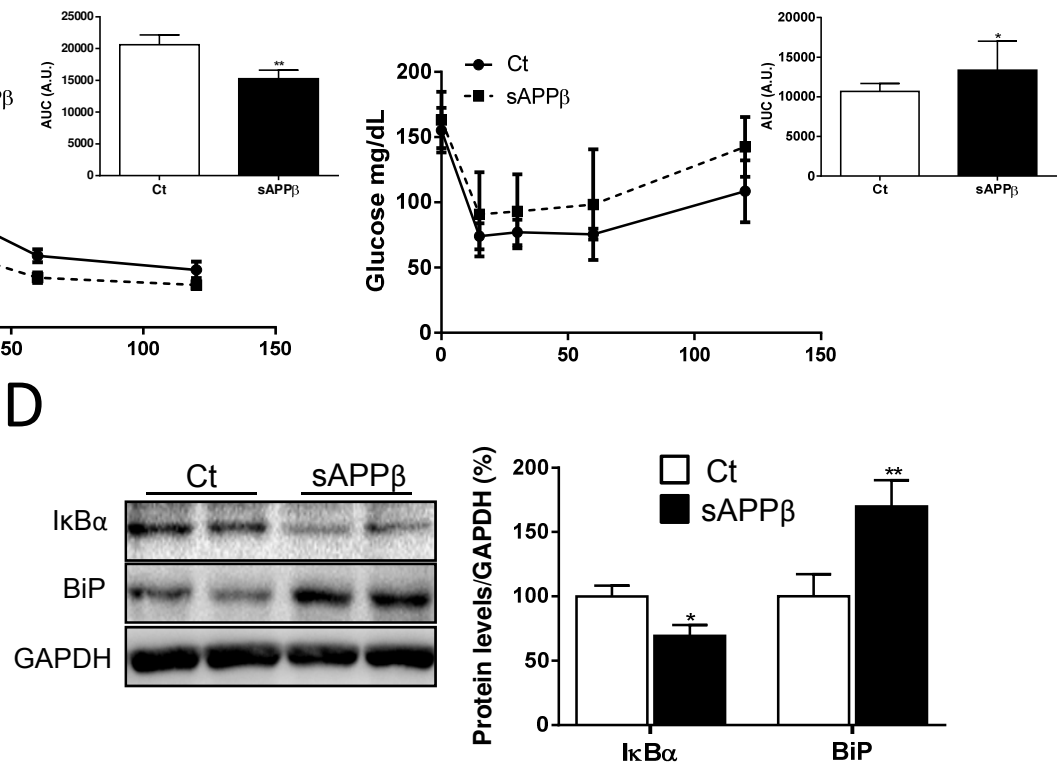

F

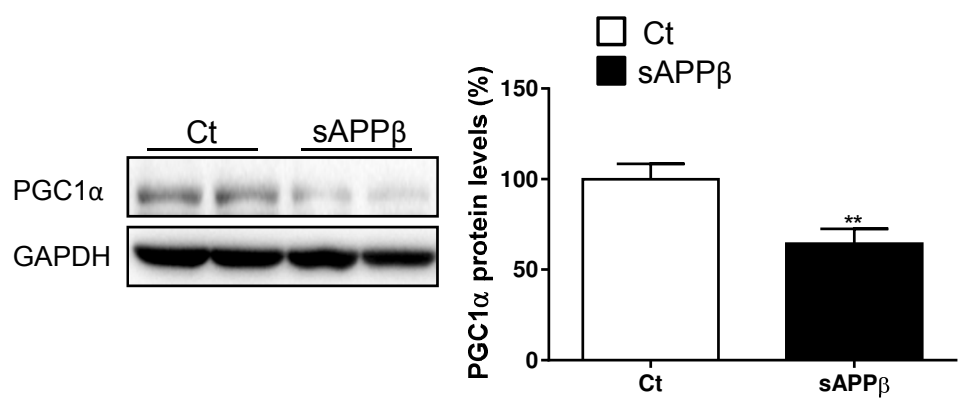

$\mathrm{H}$

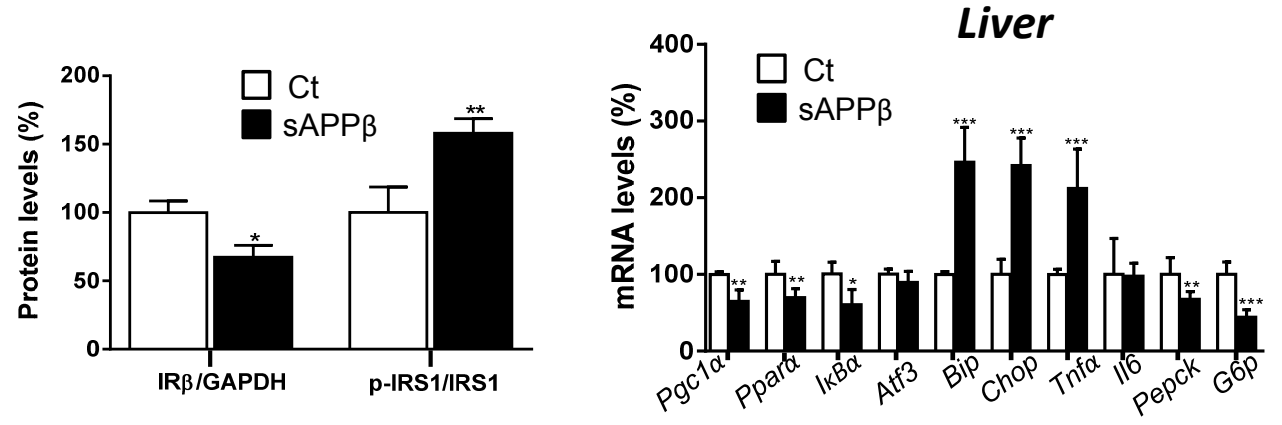

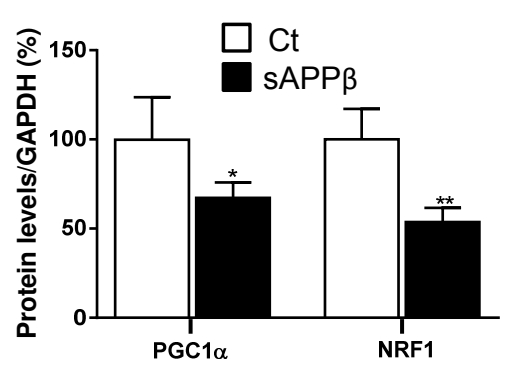

J

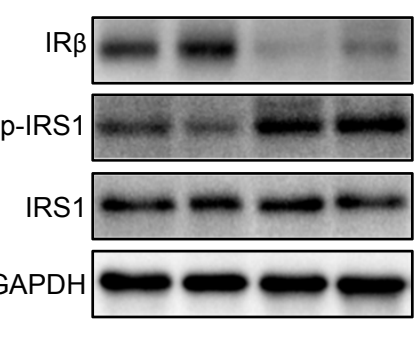

Liver

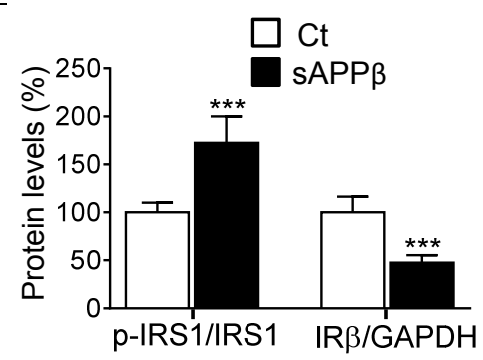



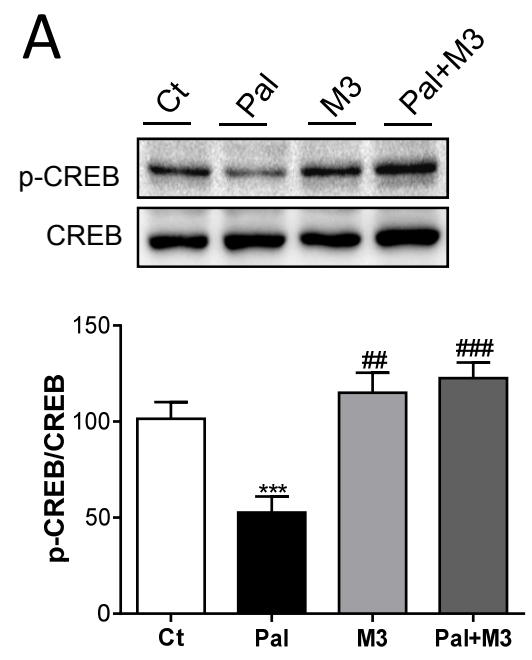

D
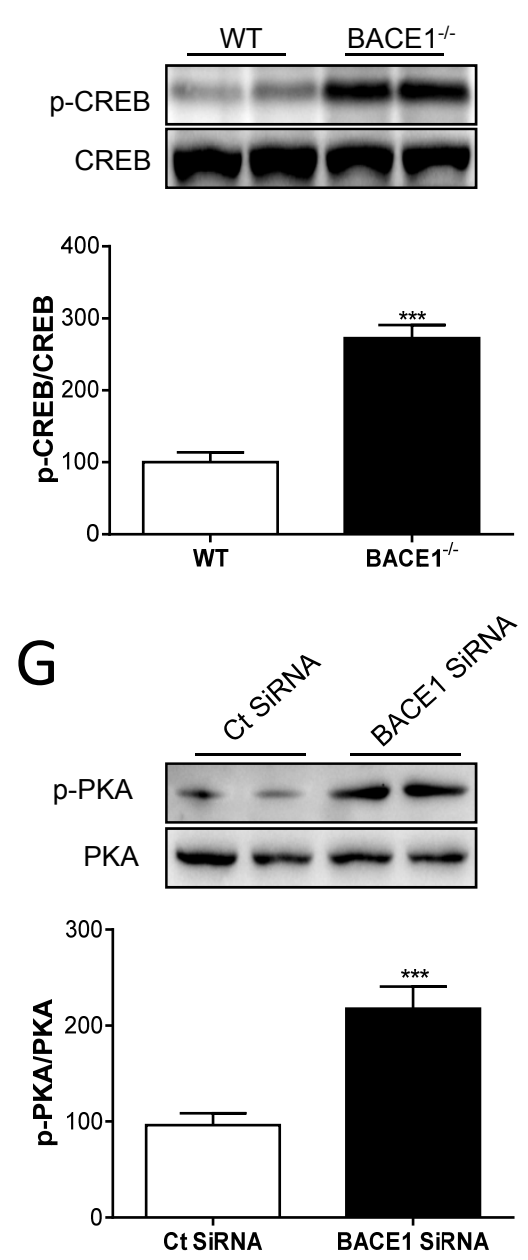

J

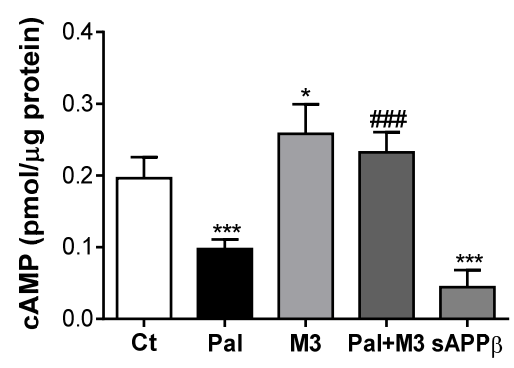

B
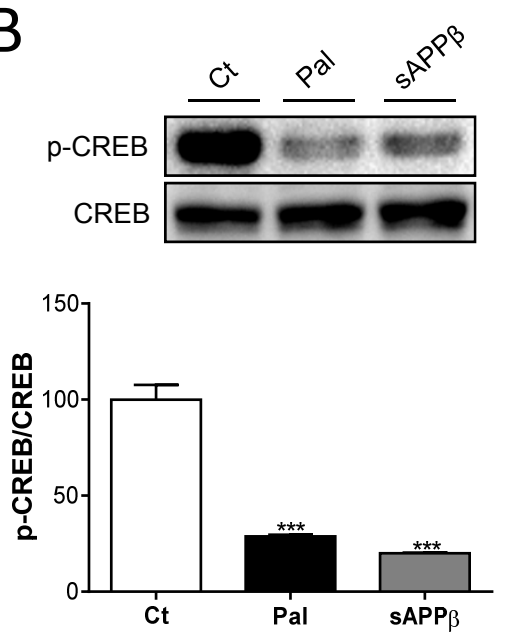

E
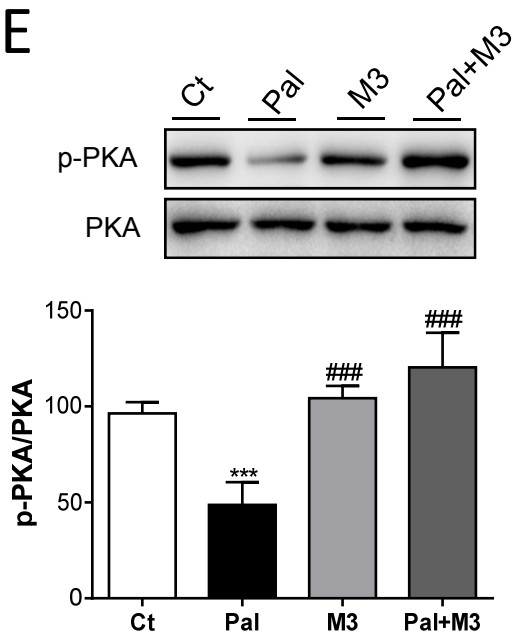

H
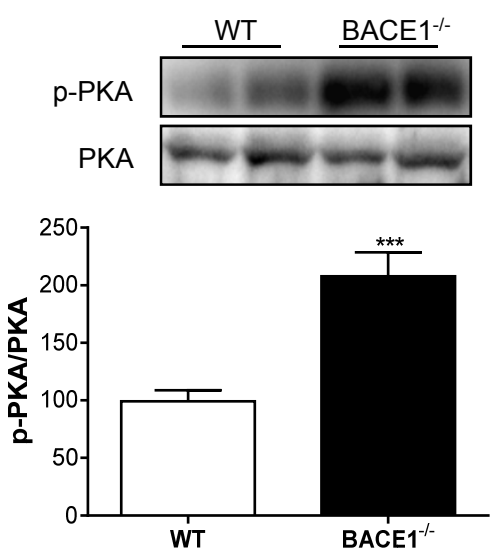

K
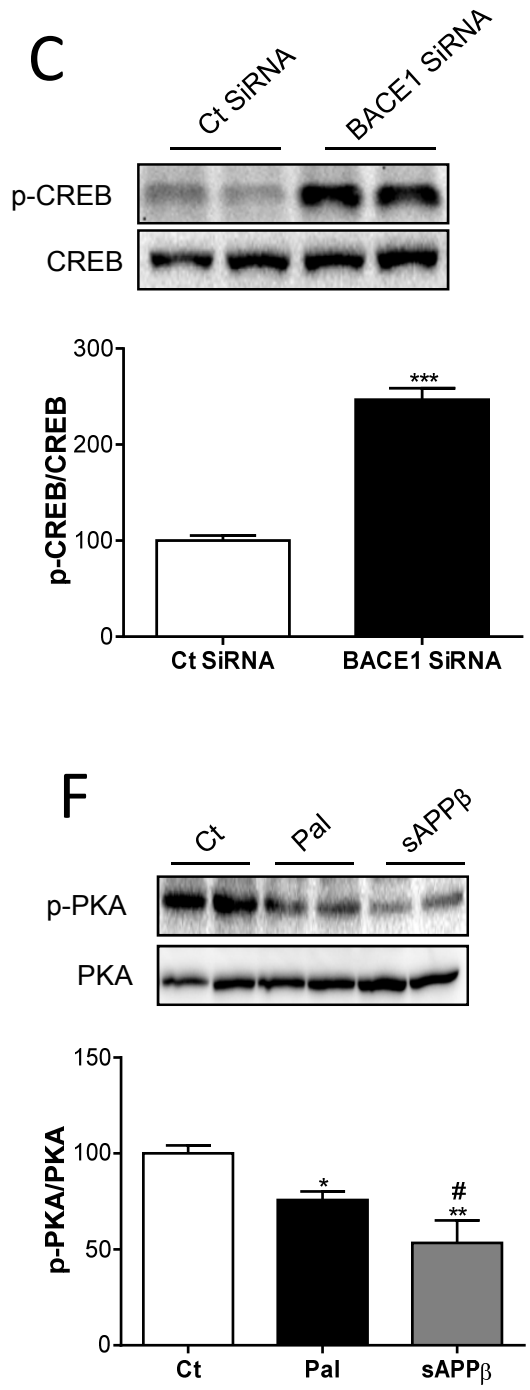

I

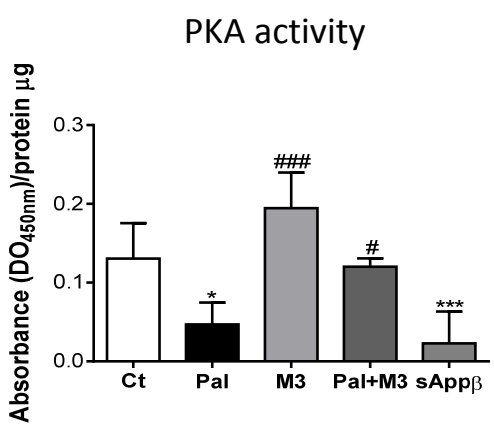

IP: AC

IP: OCT1

WB: BACE1 WB: BACE1

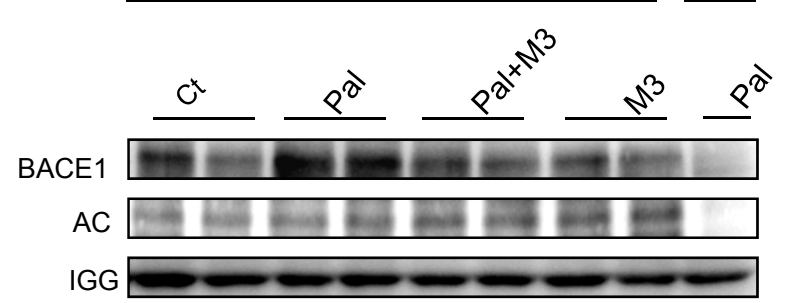

Figure 7 
A

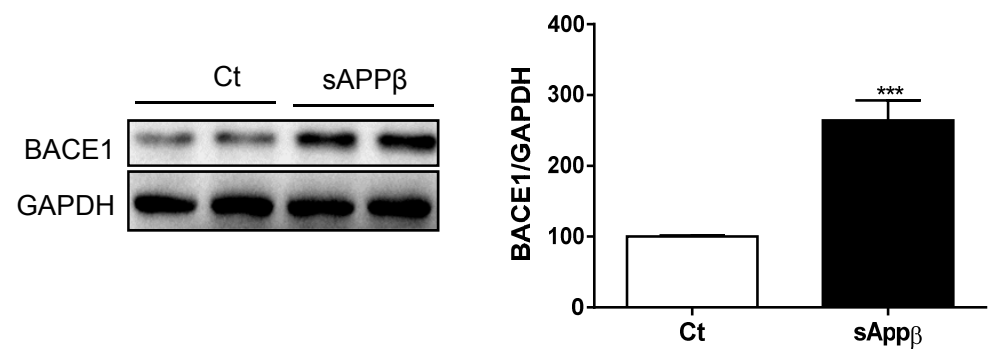

B

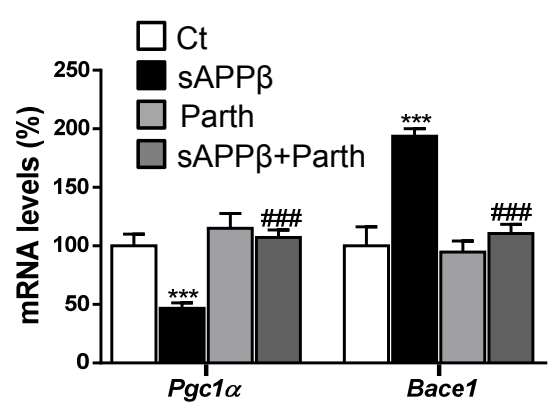

C

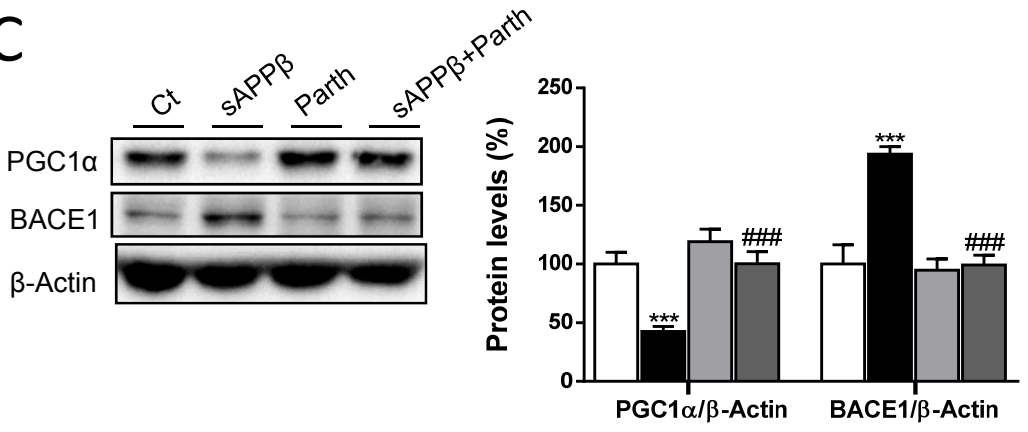

D

E
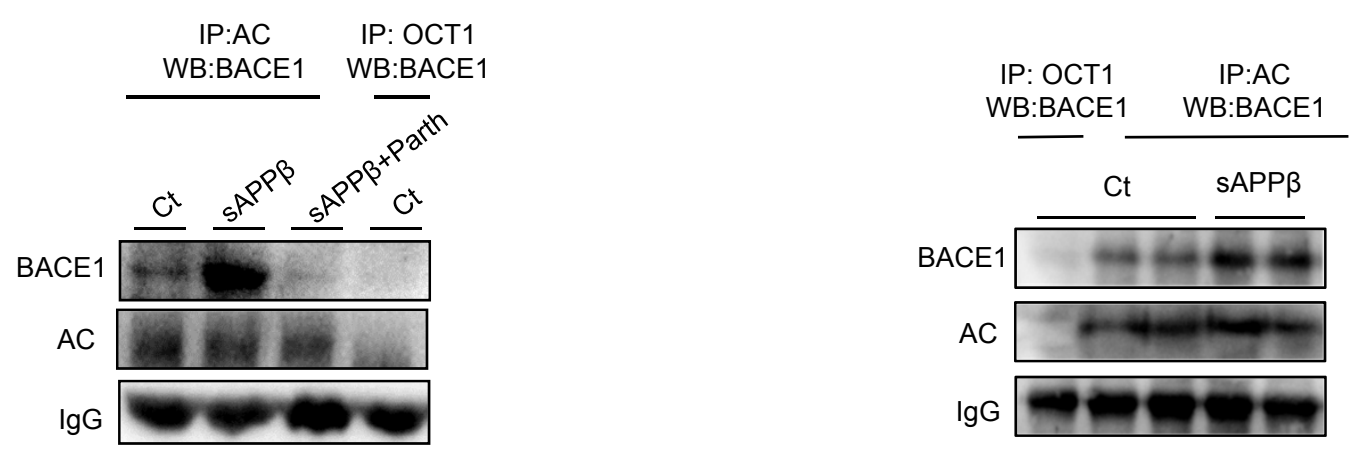

F

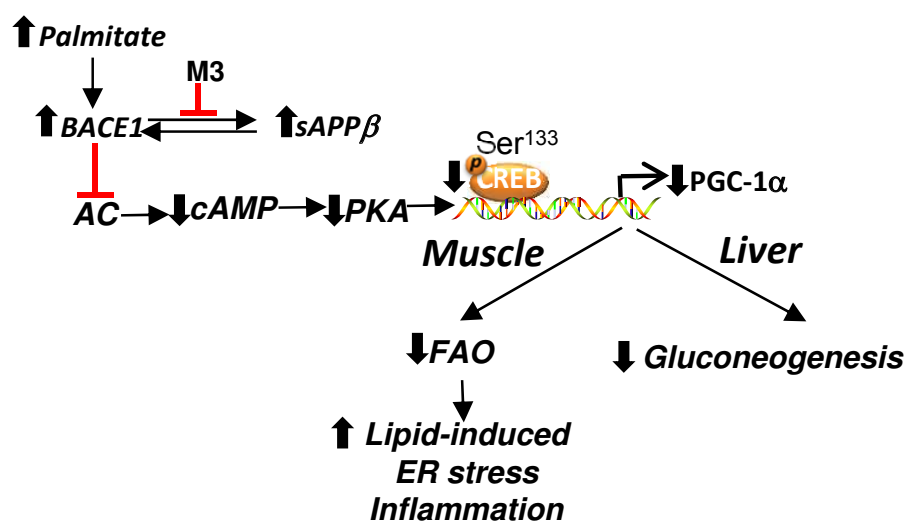

IR

Figure 8 
Supplementary Material
Click here to download Supplementary Material: Supplemental Material bis.doc

Supplementary Material
Click here to download Supplementary Material: Supplemental Material bis.doc

\begin{abstract}
Che here
\end{abstract}

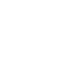

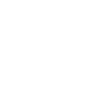

(a)

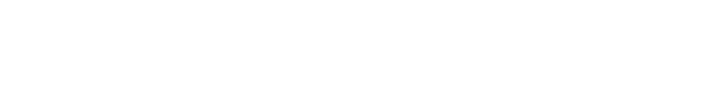

.

(1)

(1)

(1)

(1)

(1)

(1)

(1)

(1)

(1)

(1)

(2) 
Supplementary Material
Click here to download Supplementary Material: Supplementary Data.pptx

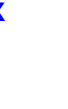

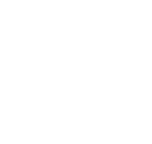

Supplementary Material: Supplementary Data.pptx

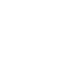

$\sqrt{2}$ (1) (1)

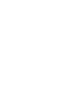

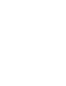
(1)

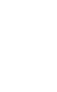
(1) (1) (1) . . . . . . . . . . . . . . . . 